\title{
Methodologies to Assess Drug Permeation Through the Blood- Brain Barrier for Pharmaceutical Research
}

\author{
Céline Passeleu-Le Bourdonnec • Pierre-Alain Carrupt • Jean Michel Scherrmann • Sophie Martel
}

Received: 14 December 2012 / Accepted: 11 June 2013 / Published online: 26 June 2013

(C) Springer Science+Business Media New York 2013

\begin{abstract}
The drug discovery process for drugs that target the central nervous system suffers from a very high rate of failure due to the presence of the blood-brain barrier, which limits the entry of xenobiotics into the brain. To minimise drug failure at different stages of the drug development process, new methodologies have been developed to understand the absorption, distribution, metabolism, excretion and toxicity (ADMET) profile of drug candidates at early stages of drug development. Additionally, understanding the permeation of drug candidates is also important, particularly for drugs that target the central nervous system. During the first stages of the drug discovery process, in vitro methods that allow for the determination of permeability using high-throughput screening methods are advantageous. For example, performing the parallel artificial membrane permeability assay followed by cell-based models with interesting hits is a useful technique for identifying potential drugs. In silico models also provide interesting information but must be confirmed by in vitro models. Finally, in vivo models, such as in situ brain perfusion, should be studied to reduce a large number of drug candidates to a few lead compounds. This article reviews the different methodologies used in the drug discovery and drug development processes to determine the permeation of drug candidates through the blood-brain barrier.
\end{abstract}

C. Passeleu-Le Bourdonnec · P.-A. Carrupt · S. Martel School of Pharmaceutical Sciences, University of Geneva University of Lausanne, Quai Ernest Ansermet 30

121| Geneva, Switzerland

J. M. Scherrmann

Neuropsychopharmacologie des Addictions

(CNRS UMR 8206, INSERM U705), Université de Paris Descartes

Université Paris Diderot, Paris, France

S. Martel $(\bowtie)$

Quai Ernest Ansermet 30, 121। Geneva 4, Switzerland

e-mail: sophie.martel@unige.ch
KEY WORDS blood-brain barrier · central nervous system . drug delivery systems · pharmacokinetics

$\begin{array}{ll}\text { ABBREVIATIONS } \\ \text { ADMET } & \begin{array}{l}\text { Absorption, distribution, } \\ \text { metabolism, excretion and toxicity }\end{array} \\ \text { AJ } & \text { Adherens junctions } \\ \text { AMT } & \text { Adsorptive-mediated transcytosis } \\ \text { ATP } & \text { Adenosine triphosphate } \\ \text { BBB } & \text { Blood-brain barrier } \\ \text { BCRP } & \text { Breast cancer resistance protein } \\ \text { CNS } & \text { Central nervous system } \\ \text { CSF } & \text { Cerebrospinal fluid } \\ \text { GLUT } & \text { Glucose transporter } \\ \text { LAT } & \text { Large aminoacid transporter } \\ \text { LDL } & \text { Low density lipoprotein } \\ \text { MRP } & \text { Multidrug resistance associated protein } \\ \text { NCE } & \text { New chemical entities } \\ \text { OATP } & \text { Organic anion transporter protein } \\ \text { PAMPA } & \text { Parallel artificial membrane } \\ & \text { permeability assay } \\ \text { PEG } & \text { Polyethylene glycol } \\ \text { P-gp/ABCBI } & \text { P-glycoprotein } \\ \text { PK } & \text { Pharmacokinetics } \\ \text { PVDF } & \text { Polyvinylidene fluoride } \\ \text { RMT } & \text { Receptor-mediated transcytosis } \\ \text { TEER } & \text { Transendothelial resistance } \\ \text { TJ } & \text { Tight junctions } \\ \text { UWL } & \text { Unstirred water layer } \\ & \end{array}$

\section{INTRODUCTION}

The high attrition rate of drug candidates during all stages of the drug development process is a critical issue for both economic and treatment reasons. It has been shown that 
the major factor leading to the attrition of new chemical entities (NCEs) during drug development does not necessarily result from a lack of drug activity but is rather a result of inadequate pharmacokinetic (PK) properties (1). Particularly for central nervous system (CNS) diseases, the lack of permeation through the BBB prevents the active compound from reaching its target. Because of the huge costs associated with bringing a drug to market, it is important to fully characterise the ADMET (absorption, distribution, metabolism, excretion, toxicity) profile of candidate drugs as early as possible during the drug discovery process. A thorough ADMET evaluation decreases the risk of attrition during clinical phases or even possible withdrawal from the market (2). ADMET issues are even more important for drug candidates that target the central nervous system (CNS). Only 3 to $5 \%$ of CNS drug candidates that enter phase I clinical trials are successfully launched compared to approximately $10 \%$ for all compounds $(2,3)$. The particular organisation of endothelial cells, which are connected by tight junctions and form the blood-brain barrier (BBB), is a further obstacle to the CNS penetration of drug candidates. Combined with numerous transporters, such as efflux and uptake transporters, and drug-metabolising enzymes present at the luminal side of the $\mathrm{BBB}$, penetration of the $\mathrm{BBB}$ is a treatment issue for CNS diseases, such as Alzheimer's disease, Parkinson's disease and Huntington's disease. By contrast, when other organs are targeted, it is critical that BBB penetration is either null or reduced to limit adverse effects. Therefore, determining the distribution of a drug in and around the brain is important when developing a new compound.

Different methodologies exist to evaluate the permeation potential of new chemical entities. The choice of strategy relies primarily on the type of throughput (driven by the number of compounds that require testing) and the type of information needed. This implies that scientists should master these strategies to choose the proper methodology based on the information required, and they should be able to correctly interpret the results. Here, we review the different methods available for physicochemists, biologists and ADMET scientists at different stages of the drug discovery and development processes to select drug candidates that penetrate the BBB. After describing the physiology of the blood-brain barrier, in silico, in vitro and in vivo approaches to determine BBB permeation will be explored. Drawbacks and advantages will be critically examined, and key experimental and/or interpretation points will be highlighted. Finally, because an increasing number of strategies to enhance drug penetration require complex formulations, such as micro/nano-carriers, application of these different screening methods to modern drug development efforts will be discussed.

\section{PHYSIOLOGY OF THE BLOOD-BRAIN BARRIER (BBB)}

In 1885, the studies of Paul Ehrlich first highlighted the presence of the BBB. In his studies, Ehrlich intravenously injected various dyes, and he observed that almost the entire body was stained but not the brain $(4,5)$.

Edwin Goldman, a student of Ehrlich's, continued this research using the dye trypan blue. He found that after intravenous injection of the dye, the choroid plexus and meninges were stained; however, no dye was recovered in either the brain or cerebrospinal fluid (CSF) (6). In another experiment, he injected the dye directly into the CSF and found that the entire brain was stained but not the rest of the body (7). These experiments demonstrated the existence of a biological barrier between the brain and the rest of the systemic circulation, the blood-brain barrier.

Over many years of research, our knowledge of the BBB has increased, and scientists are now aware that the BBB is a structure with complex cellular organisation that separates the brain parenchyma from the systemic circulation. It is of key importance for the maintenance of brain homeostasis, which is essential for good neuronal and synaptic activities (8-12), and represents the main route by which compounds reach the CNS. Moreover, the BBB also acts as a metabolic barrier due to the presence of numerous enzymes $(13,14)$, including peptidases, $\gamma$-glutamyl transpeptidase $(\gamma$-GT), alkaline phosphatase (ALP), nucleotidases, cytochromes P450 (CYP450) and monoamine oxidase (MAO). These enzymes can either metabolise potentially harmful drugs to inactive CNS compounds, convert an inactive drug to its active CNS metabolite or degrade them into metabolites or substrates of specific efflux transporters, such as the P-glycoprotein or multidrug resistance proteins.

The BBB consists of brain capillaries that support endothelial cells and are surrounded by astrocytic end-foot processes (15). It is the central part of the neurovascular unit, which is responsible for communication between endothelial cells, astrocytes, pericytes and neurons (14).

\section{Endothelial Cells and Tight Junctions}

The specificity of the endothelial cells comprising the bloodbrain barrier compared to the endothelial cells in the rest of the body is based on their organisation. Cerebral endothelial cells are connected by intercellular proteins. Occludins, claudins and junctional adhesion molecules, together with cytoplasmic accessory proteins, including zonula occludens1 (ZO-1), ZO-2, ZO-3 and others, are transmembrane proteins that are responsible for the formation of tight junctions (TJs) (14) that seal the paracellular pathway (16-18) and make the brain nearly inaccessible to polar compounds that are not the substrates of specific transporters (19). Adherens 
junctions $(\mathrm{AJs})$ also contribute to the junction complex by joining the membrane proteins, cadherins, to the intermediary proteins, catenins, to form adhesive linkages between endothelial cells (20). The TJs in cerebral capillaries are approximately 50 to 100 times tighter than the TJs in peripheral capillaries (21) and lead to a high transendothelial electrical resistance (TEER) of approximately 1,500-2,000 $\Omega . \mathrm{cm}^{2}$ compared to $3-33 \Omega . \mathrm{cm}^{2}$ for other tissues $(22,23)$, which is due to the restriction of small ions, such as $\mathrm{Na}^{+}$and $\mathrm{Cl}^{-}$, from passing through the TJs. Moreover, BBB endothelial cells differ from other endothelial cells in the low number of endocytotic invaginations at the luminal portion of the cell membrane, which leads to very limited pinocytic transcellular transport (12,20,24-28), a large number of mitochondria (29) and the polarised expression of transporters and receptors for active transport (30). Indeed, the brain endothelium has only 3-6 pinocytic vesicles per $\mu \mathrm{m}^{3}$ compared to 82-93 per $\mu \mathrm{m}^{3}$ for the peripheral endothelium $(31,32)$.

Many transmembrane proteins are expressed on the luminal and abluminal membranes of the endothelium to transport nutrients that are essential for the brain and to eliminate waste products of metabolism. In particular, proteins, such as GLUT-1 (glucose transporters), transport polar nutrients; Na-ATPase and K-ATPase transport sodium and potassium ions respectively; insulin or transferrin receptors transport proteins $(8,24,28,33,34)$, and organic anion transporting proteins (OATP) (35) transport hormones, opioids, steroids, statins, cardiac glycosides, anticancer drugs and antibiotics (15). These transporters all play important roles in the maintenance of cerebral equilibrium. Moreover, efflux transporters, such as P-gp/ABCB1(36) or BCRP (37) are highly expressed on the luminal side of endothelial cells.

\section{Astrocytes, Pericytes and Basal Lamina}

Astrocytes are important cellular constituents of the neurovascular unit. They are linked to interneurons and thus the entire cerebral microenvironment (19). Astrocytes represent approximately $50 \%$ of the total mammalian brain volume (38). Moreover, some studies indicate that astrocytes play a role in the upregulation of BBB properties, such as tighter tight junctions $(39,40)$ and the expression of specific polarised transporters, such as $\mathrm{P}-\mathrm{gp} / \mathrm{ABCB} 1(14)$ and the enzymatic system $(14,19)$, due to astrocyte-endothelial cell interactions. This upregulation of BBB properties by astrocytes is synergistic with pericytes, neurons and perivascular macrophages (41). Astrocytes also have different functions, such as the formation of and activity at synapses, energetic and redox metabolism, intercellular communication, homeostasis (38) and glucose transport from the systemic circulation to the brain.

Similar to astrocytes and neurons, pericytes are part of the neurovascular unit and play a role in the maintenance of both BBB properties and cerebral homeostasis. Recent studies have also indicated a role for pericytes in haemostasis, as well as in immune and phagocytic processes $(20,42)$. Pericytes surround endothelial cells and both cell types are supported by the basal lamina. The integrity of basal lamina allows the maintenance of BBB properties, due to its anchoring role, but the basal lamina does not have a significant impact on the permeability of the BBB. However, under specific pathological conditions or in response to an aggressive stimulus, its thickness can vary, which perturbs the normal function of the BBB (42).

\section{MECHANISMS OF TRANSPORT THROUGH THE BBB}

The BBB is one of the most important barriers in the body. The permeation of drugs through the BBB is subject to strong selection depending on the physicochemical properties of the compound, such as lipophilicity, molecular weight, permeability coefficient $\left(\log \mathrm{P}_{\mathrm{e}}\right)$, molecular volume, ionisation state, and/or their affinity to specific transporters(efflux or uptake transporters) that are present in the cellular space (43-45). Therefore, the BBB may not be as impermeable as indicated by the first experiments with dyes. The cellular organisation of the BBB and the presence of transmembrane proteins enable a selective regulation of the passage of molecules from the blood to the brain. This is of particular importance for the uptake of essential nutrients or active CNS drugs and protects the brain from undesirable compounds, which could be toxic to the GNS.

The specificities of brain capillaries makes of the BBB an effective and efficient barrier that limits the entry of xenobiotics into the brain. Molecules present in the blood stream can reach the CNS by two different pathways, the paracellular pathway, which is between 2 endothelial cells through the tight junctions, or the transcellular pathway, which is through an endothelial cell.

Molecules that reach the CNS via the transcellular pathway can diffuse passively, can be actively transported by specific transporters or can undergo endocytosis. For example, small lipophilic molecules, such as $\mathrm{O}_{2}$ and $\mathrm{CO}_{2}$, or very small compounds, such as ethanol, water or diverse lipophilic drugs, can freely diffuse through the lipid barriers of endothelial cells (19).

\section{Paracellular Pathway}

The paracellular pathway is a diffusion process that occurs between 2 cells. This pathway is limited to small hydrophilic molecules such as cimetidine, ranitidine, famotidine $(46,47)$ and furosemide (48), which are hypothesised to be absorbed via the paracellular pathway in the intestinal track, due to the 
aqueous surroundings of the cells (49). However, due to the presence of tight-junctions between two cerebral endothelial cells, this route is extremely limited and nearly non-existent at the BBB, although under some pathological conditions, tight junctions and adherens junctions between endothelial cells may be altered. This alteration enables leakage, which can allow passage of plasma proteins, fluids or immune cells into the brain $(12,19,50-55)$. The selectivity of this route is limited to either size or shape features.

\section{Transcellular Pathway}

Complex tight junctions force therapeutic molecules to follow a transcellular pathway through the BBB rather than the paracellular pathway as in most endothelia (19).

\section{Passive Diffusion at the $B B B$}

Passive diffusion is one of the most straightforward mechanisms of permeation. This process requires a concentration gradient but no energy and no specific protein carriers. Diffusion requires physicochemical interactions between the compound and the membrane that must be crossed $(43,44)$. Moreover, because there is no specific binding site, passive transport is not affected by stereochemistry and there is no saturation and no possible inhibition of the diffusion process (56). These observations indicate that passive diffusion is concentration-independent: the process occurs till equilibrium between the blood and the brain.

Passive diffusion through the BBB is highly affected by lipophilicity and the size of the compound (57-59). It was demonstrated that compounds with a molecular weight greater than 500-600 Da poorly permeated the BBB $(60,61)$. However, when combined with good lipid solubility, molecules with molecular weights greater than 500 Da have interesting BBB permeability characteristics (62). Similarly, the lipophilicity of compounds should be high enough to allow for good affinity with lipidic membranes, but the lipophilicity should not be too high so as to avoid trapping of the compound in the membrane and bioaccumulation. By contrast, due to the hydrophobic nature of the membrane, ionisation will greatly impact diffusion because ionised compounds are highly hydrophilic and therefore have poor interactions with the membrane (63).

\section{Carrier-Mediated Transport at the BBB}

A certain number of uptake or efflux proteins are expressed at the BBB. These transporters are present on the luminal and abluminal membranes of the endothelium and regulate the entry of their specific substrates $(19,64)$. Uptake proteins transport molecules from the blood to the brain. These transport systems allow the permeation of essential cerebral nutrients, such as glucose or amino acids, and either limit or prevent the passage of undesired or potentially toxic molecules. By contrast, efflux proteins, such as P-glycoproteins (P$\mathrm{gp} / \mathrm{ABCB} 1)$, multidrug-resistance multidrug resistance associated proteins (MRP) or the breast cancer resistant protein (BCRP) (65), excrete their substrates out of the brain by pumping the substrates into the blood stream. At the BBB, $\mathrm{P}$-gp/ABCB1 are highly expressed and a certain number of NCEs are substrates for this protein (56).

Carrier-Mediated Uptake. Carrier-mediated transport can be either active or facilitated. When the transport of a substrate needs either direct energy which requires ATP binding and hydrolysis to mediate the primary active transport process, such as transporters of the ABC superfamily, or indirect energy, which is driven by ion gradients that result from ATP-dependent primary transport, such as many transporters of the SCL superfamily, it is active carrier-mediated transport, whereas when transport requires only a concentration gradient and a transporter protein, it is facilitated carrier-mediated transport. Both types of transport are saturable, competitive and stereospecific (56). Moreover, these types of transport imply a specific interaction between the carrier proteins and the substrate.

Some examples of transporters are the glucose transporter (GLUT-1), the monocarboxylic acid transporter (MCT1), the large neutral amino-acid transporter (LAT1) and the organic anion transporters (OATP) $(32,66)$. Specific transporters are also present for small ions, such as $\mathrm{Na}^{+}, \mathrm{K}^{+}$or $\mathrm{Cl}^{-}$, in both the blood to brain and brain to blood directions. These ion transporters maintain brain homeostasis because ionic disequilibrium between the blood and brain can have serious effects, such as brain oedema.

Efflux Transport. Efflux transport is an energy-dependant, active process, which pumps xenobiotics and metabolites out of the brain into the blood stream. The most wellknown and studied efflux proteins belong to the ATP binding cassette $(\mathrm{ABC})$ family, including the P-glycoproteins ( $\mathrm{P}$ $\mathrm{gp} / \mathrm{ABCB} 1$ ), which are encoded by the multidrug resistance gene 1 (MDR1/ABCB1), the multidrug resistance associated protein (MRP) and the breast cancer resistance proteins (BCRP). These active transport processes are essential for brain protection because they prevent the cerebral penetration of potentially harmful drugs and also excrete waste products and metabolites. The expression of most efflux proteins is regulated by astrocytes or pericytes (67).

\section{Trans- and Endocytosis Mechanisms}

Brain penetration is not strictly limited to small lipophilic molecules or compounds shuttled by uptake proteins. Larger 
molecules, such as peptides, proteins or even viruses, which are too large for a carrier-mediated process, can also penetrate the BBB via the few pinocytic vesicles that are present in endothelial cells. These large molecules can be transported either by receptor-mediated transcytosis (RMT), adsorptive-mediated transcytosis (AMT) (10) or fluid phase endocytosis (32).

During RMT, the ligand specifically binds to the receptor protein and is transported through the cell. The best characterised and utilised RMT protein is most likely the transferrin receptor, which has also been extensively studied for the delivery of immunoliposomes. Other well-known receptors include the low-density lipoprotein (LDL) receptor and the insulin receptor (32).

During AMT, a non-specific interaction occurs between the solute and the surface protein. Peptides, glycopeptides, glycoproteins, and viruses are transported by this pathway (32).

During a fluid phase endocytosis event, there is no contact between the solute and the protein. The substrate is situated close to the membrane, which deforms and encircles both the solute and some extracellular fluid and transports the entire vesicle to the abluminal side. Lucifer yellow is transported in this manner (32).

\section{STRATEGIES FOR IMPROVING BRAIN PENETRATION}

The BBB is a serious obstacle for the treatment of neurodegenerative diseases that require CNS action (43). Because of its physical organisation, the BBB prevents the passage of many drugs that target the CNS. Therefore, even if a potential drug has potent activity against its target, it may not be able to cross the BBB and will most likely be discarded during the drug development process. Moreover, metabolic features of the BBB may also prevent a CNS active drug from crossing the endothelial membrane because the therapeutic efficacy of the drug can be either inactivated or decreased by enzymes at the BBB. To circumvent the BBB and allow an active CNS compound to reach its target, many strategies exist, which may be either invasive or non-invasive with respect to the $\mathrm{BBB}$.

\section{Invasive Techniques}

\section{Direct Injection into the Cerebrospinal Fluid}

Direct injection of drugs into the cerebrospinal fluid was the first strategy used to circumvent the $\mathrm{BBB}$, primarily to target brain tumours. This technique is not very efficient because there is a poor diffusion between the cerebrospinal fluid and the brain and it is quite invasive (68). Nau et al. demonstrated a 3-fold increase in the mortality of infants with Gram- negative meningitis treated with an intraventricular injection of aminoglycosides combined with intravenous injections of antibiotics compared to intravenous injection of antibiotics alone (68).

\section{Therapeutic Opening of the $B B B$}

Therapeutic opening of the $\mathrm{BBB}$ is a reversible process. Because of specific molecules which generate a hyperosmolar environment, the BBB loses its barrier properties, thus enabling passage of the therapeutics into the brain before the BBB regains its functions. A transient brain opening is generally obtained by intra-carotid injection of mannitol or alkyl glycerol, which creates hyperosmolar conditions on the systemic circulation side of the BBB and causes a reversible shrinkage of the endothelial cells and a loss of adherens and junctional proteins, leading to a paracellular opening between endothelial cells $(69,70)$. However, depending on the mediator used to momentarily disrupt the $\mathrm{BBB}$, an increase in transcellular permeability can also occur, such as with tumour necrosis factor $\alpha$, which leads to the permeation of opportunistic toxic compounds. Moreover, the duration of the opening of the BBB will depend on the mediator used. Histamine provides a rapid and temporary opening, whereas thrombin causes drastic modifications of the endothelial cytoskeleton resulting in prolonged opening of the BBB with difficulties in returning to the basal state $(51)$.

This difficult strategy must be handled with care and vigilantly monitored to prevent damage to the brain parenchyma and oedema, which may be fatal. However, when performed properly, therapeutic opening of the BBB allows for the delivery of active drugs into the GNS, which would not otherwise reach the brain. This strategy is primarily used for the treatment of brain tumours or life-threatening diseases that have not been cured with less invasive treatments.

\section{Non-Invasive Techniques}

Brain penetration can be improved either using an alternative administration route, inhibiting efflux transporters, chemically modifying or encapsulating the active compound.

\section{The Nose-to-Brain Route}

To circumvent the BBB and enter the brain parenchyma, alternative strategies for drug delivery, such as the nose-tobrain route, are useful. In the nose-to-brain pathway, the therapeutic compound can be directly transported to the brain by absorption in the nasal mucosa and transport via the olfactory routes $(71,72)$. Therefore, localisation of the olfactory route close to a brain region that is exempt of $\mathrm{BBB}$ allows for the circumvention of the barrier, which allows the 
drug to reach the CNS (73). This route has been evaluated for the permeation of cocaine (74), as well as formulations such as the alprazolam-loaded solid lipid nanoparticles (75) or even neuropeptides (76). This strategy suffers primarily from poor bioavailability, which ranges from $0.01 \%$ to $0.1 \%$ (72).

\section{Inhibition of Efflux Transporters}

The presence of numerous efflux transporters at the BBB prevents the entry of many CNS active compounds into the brain. In HIV treatment, the most efficient drugs, such as abacavir and efavirenz, are substrates of the ABC transporters. Therefore, an interesting strategy is to inhibit efflux transporter activity and saturate these transporters with substrates that have higher affinity than the drug (77). This strategy is efficient in HIV multi-therapy and improves the intracerebral concentration of HIV protease inhibitors (33). However, this strategy may have several drawbacks because inhibition of efflux transporters will allow the penetration of other xenobiotics, which may be potentially toxic in the CNS. Therefore, adverse side effects may occur using this strategy.

\section{Use of Prodrugs}

Pharmacology-based strategies are methods to either enhance the lipophilicity of a drug candidate to favour its passive permeation (78) or to mask the specific site recognised by efflux transporters. The primary goal of this strategy is to promote the permeation of compounds that have either low uptake or are substrates of efflux transporters in their native form. The addition of moieties to the drug, which are linked by covalent reversible bonds, allows for the physicochemical modification of the active compounds to cross the BBB. For example, dopamine, a treatment for Parkinson's disease, cannot cross the BBB and enter the central nervous system where its target is located. Therefore, carbonylation of dopamine allows for the active transport of the inactive prodrug form through the BBB. After the prodrug has entered the brain, DOPA decarboxylase activates L-Dopa into active dopamine. This strategy also permits the creation of a drug-reservoir, depending on the rate of liberation of the native active compound. This approach is, therefore, an asset for patient compliance. However, chemical modification of the native active drug may decrease its activity or bioavailability.

\section{The Trojan Horses or the BBB Shuttles}

The concept of a Trojan horse consists of coupling the drug of interest, which cannot penetrate the BBB, to a compound, such as a molecule, peptide, or transferrin, that crosses the $\mathrm{BBB}$ via an active process uptake transporter, such as the glucose transporter (GLUT-1) or transferrin receptor. The BBB-penetrating moiety is recognised by the specific receptor, leading to transport of the entire molecule, including the drug (78). An extension of this concept was proposed by Malakoutikhah and co-workers (79) who designed peptidic Trojan horses that were able to cross the BBB via passive diffusion. These compounds were defined as BBB shuttles. The challenge of both Trojan horses and BBB shuttles is to then liberate the active drug from the vector.

\section{Drug Delivery with Nanocarriers}

Liposomes, polymeric nanoparticles, solid lipid nanoparticles and micelles are all nanocarriers and have garnered great interest in recent pharmaceutical research. Because of the incorporation of a drug into the inside core of the nanocarrier, the drug bioavailability, physicochemistry and pharmacokinetics of the drug are changed $(80,81)$. In pharmaceutical research, a well-known problem is the discovery and development of highly potent lead compounds, which are then found to be either insoluble or poorly soluble. In most cases, either the molecule will be discarded from the drug development process, or a ligand strategy will be used to enhance the solubility of the potential drug, with the risk of decreasing its potency.

Drug delivery is a method of bypassing poor solubility, poor permeability or poor bioavailability by incorporating the compound of interest into either phospholipidic, polymeric or inorganic vesicles (82).

Liposomes consist of a phospholipid bilayer; therefore, they allow for the incorporation of either hydrophilic molecules, on the inside core, or lipophilic molecules, inside the bilayer (82). These liposomes are extensively studied and highly promising nanocarriers, particularly for cancer therapy. Caelyx ${ }^{\circledR}$, a pegylated liposomal formulation of doxorubicin that targets breast cancer cells, is a good representative of the success of these formulations $(83,84)$.

Three generations of liposomes have now been developed. The first generation consists only of a vesicle formed by a phospholipid bilayer. These types of liposomes are rapidly recognised by the reticuloendothelial system and eliminated. Therefore, their efficacy is very limited and not applicable for pharmaceutical purposes. The second generation of liposomes is surrounded by polyethylene glycol, which is covalently linked to the outer part of the vesicle. These pegylated liposomes have a longer circulation time in the body because PEG is not recognised as a foreign body by the immune system. The third generation of liposomes is the most potent generation of liposomes. These liposomes consist of the same pegylated liposomes as the second-generation liposomes but are functionalised with specific moieties, such as monoclonal antibodies, added to the PEG chain. Therefore, the modified liposome is recognised by the 
antibody-specific receptor and may be taken up by the cell. This strategy allows for specific targeting of cells. For example, immunoliposomes, grafted with OX26 monoclonal antibody are able to recognize transferrin receptor at the $\mathrm{BBB}$, which transport it through the a rat BBB model via endocytosis (85). Up to now, many immune-conjugated nanocarriers are on clinical phases such as doxorubicin, anti-REH-2 (86), but none has launched the market yet. Future years will probably disclose numerous new formulations aiming at treating CNS pathologies.

The major drawback of liposomes is their poor stability, which is due to their tendency to aggregate and their sensitivity to oxidation and hydrolysis. Some of these problems can be reduced by formulation strategies, such as the addition of $\alpha$-tocopherol to decrease oxidation (87). Other researchers have formulated liposomes as proliposomes, a dry granular product, which disperses to form multi-lamellar vesicles upon the addition of water (88).

Nanoparticles as drug carriers have also been extensively studied recently. Their uptake into the brain is hypothesised to occur via receptor-mediated endocytosis (89,90). Because unmodified nanoparticles have been shown to be rapidly cleared by the reticuloendothelial system, within $5 \mathrm{~min}$ in a mouse model, surfactants or covalent binding of polyethylene glycol on the polymeric core led to a prolonged circulation time and improved bioavailability (91). Only a few nanoparticle formulations of drugs are currently on the market (92), such as Rapamune ${ }^{\circledR}$, an immunosuppressant drug. Promising results have been obtained in preclinical studies of a glioblastoma rat model, using doxorubicin-incorporated nanoparticles; however, no CNS-targeting nanoparticles are currently available in the market. Nanoparticles can either be polymeric, lipidic or inorganic. The safety profile of these vesicles is controversial, and much research is necessary to fully describe the mode of excretion, the possible accumulation of particles in organs and the side effects caused by these nanoparticles.

\section{METHODS TO ASSESS BBB PERMEABILITY INFORMATION IN DRUG RESEARCH}

\section{In Silico Models That Predict BBB Permeability}

In silico models are used during the early stages of the drug discovery process when thousands of compounds must be screened for either interactions with a specific target or for the appropriate physicochemical properties. For example, Lombardo et al. (93) succeeded in predicting the blood-brain partitioning of compounds (log BB) using the calculated solvation free energy. Others correlated log BB with a combination of the molar refraction, solute polarisability, hydrogen bond donor or acceptor capacity and molecular volume $(94,95)$. In silico strategies can filter large databases to preselect compounds of interest and can predict whether a compound will be prone to BBB penetration or not (96). These computational strategies can decrease the number of molecules to only few hit compounds, which are then tested with in vitro models to determine the pharmacokinetics and mechanism of action of the drug.

In silico models combine the measured brain penetration information that is available in the literature with molecular properties to build an algorithm that can predict BBB permeability. Using partial least squares regression, multiple regression analysis or neural networks, in silico models can generate ponderated regressions consisting of different physicochemical properties, such as the lipophilicity $(\log \mathrm{P})$, standard free energy, H-bond donating capacity, H-bond accepting capacity, and molecular weight of the drug.

In practice, the initial data, which are obtained from libraries, are divided into 2 subtest sets, a training set, which is used to build the algorithm, and a test set, which allows for determination of the predictive ability of the algorithm. The experimental permeabilities of the test set are statistically compared to the predicted values that are generated by the algorithm to determine this predictive power (96). The variety of algorithms that are able to build a predictive model is huge because many descriptors may be used to generate an equation. Some examples of in silico models to predict $\log \mathrm{BB}$ are listed in a review of Abraham (96). In general, the chosen descriptors are related to the size of the molecules and their physicochemical properties. As Abraham noted, an increase in size-related descriptors leads to an increased $\log \mathrm{BB}$ (higher brain penetration), whereas an increase in the polarity-related descriptors leads to a decreased log BB. This characteristic is linked to the physicochemistry of both compartments, with the brain being more lipophilic than the blood. Moreover, Didziapetris et al. (97) suggested that acids with a $\mathrm{pKa}>4$, containing greater than 8 oxygen and nitrogen atoms and a molecular weight greater than 400 Da were likely to be substrates of efflux proteins.

A major issue resulting from in silico models is the reliability of the chosen training sets and test sets. It is difficult to obtain experimental data that are homogeneous in terms of the experimental design, such as whether the perfusion was performed with whole blood, plasma or saline solutions, the reliability of descriptors, such as whether there was ionisation, and the experimental know-how. The ideal situation would be to obtain the experimental data from the same laboratory, under the same conditions; however, that situation is utopic because the amount of data would be either too low to build the model or not diverse enough. Therefore, attention should be paid when handling in silicopredicted data, and the user must also understand how the model was built. 


\section{In Vitro Models for Prediction of BBB Permeability}

Different approaches have been proposed for the in vitro evaluation of whether a new chemical entity can cross the BBB. Significant differences exist from one method to another in terms of complexity and, consequently, cost and information obtained (Fig. 1). In this section, in vitro methods for predicting $\mathrm{BBB}$ permeability are ordered according to increasing complexity.

\section{Immobilised Artificial Membrane}

Lipophilicity ( $\log \mathrm{P}$ or $\log \mathrm{P}_{\text {octanol/water }}$ ) has long been reported to be a major parameter that influences CNS activity and the blood/brain concentration ratio (log BB) $(98,99)$. Because of its lipophilic feature, n-octanol was widely used for pharmacokinetic predictions. The small polar head of n-octanol and its hydrophobic carbonylated chain make it appear similar to phospholipidic membranes. However, the relationship between $\log \mathrm{P}$ and $\log \mathrm{BB}$ is not strong enough for the needs of CNS researchers. Therefore, immobilised artificial membranes (IAMs) were proposed as an alternative to $\log \mathrm{P}$ predicted with shake flask or liquid chromatography (100-103). Modified HPLC columns were prepared in which phospholipids were covalently bound to the silica (99). Experiments showed a linear relationship between the retention factors on IAMs and the partition between an aqueous phase and liposomes (104). Moreover, IAM chromatographic retention factors were shown to generate information on membrane permeability (105). In some cases, these types of systems have shown reasonable results for permeability prediction, even if the retention time on the column does not reflect transport across the membrane $(106,107)$. However, there are some limitations in terms of retention times for lipophilic compounds and stationary phase stability. Recently, short IAM columns appeared on the market. These columns (1-3 cm versus $10-12 \mathrm{~cm}$ ) allow greater throughput but do not really offer any improvements in terms of reliability, and this approach is not widely used in drug discovery.

\section{PAMPA Models}

The parallel artificial membrane permeability assay (PAMPA) is a relatively recent technique developed in 1998 by Kansy et al. (108) to rapidly predict passive permeability through the gastrointestinal tract with high throughput efficiency. In this technique, a donor and an acceptor compartments are separated by a filter supporting a liquid artificial membrane. The drug to be tested, placed in the donor compartment, can then permeate between the donor and the acceptor compartments through the artificial membrane. The assay is performed in 96-well plates and thus enables high throughput screening. The permeability coefficient is then determined in a

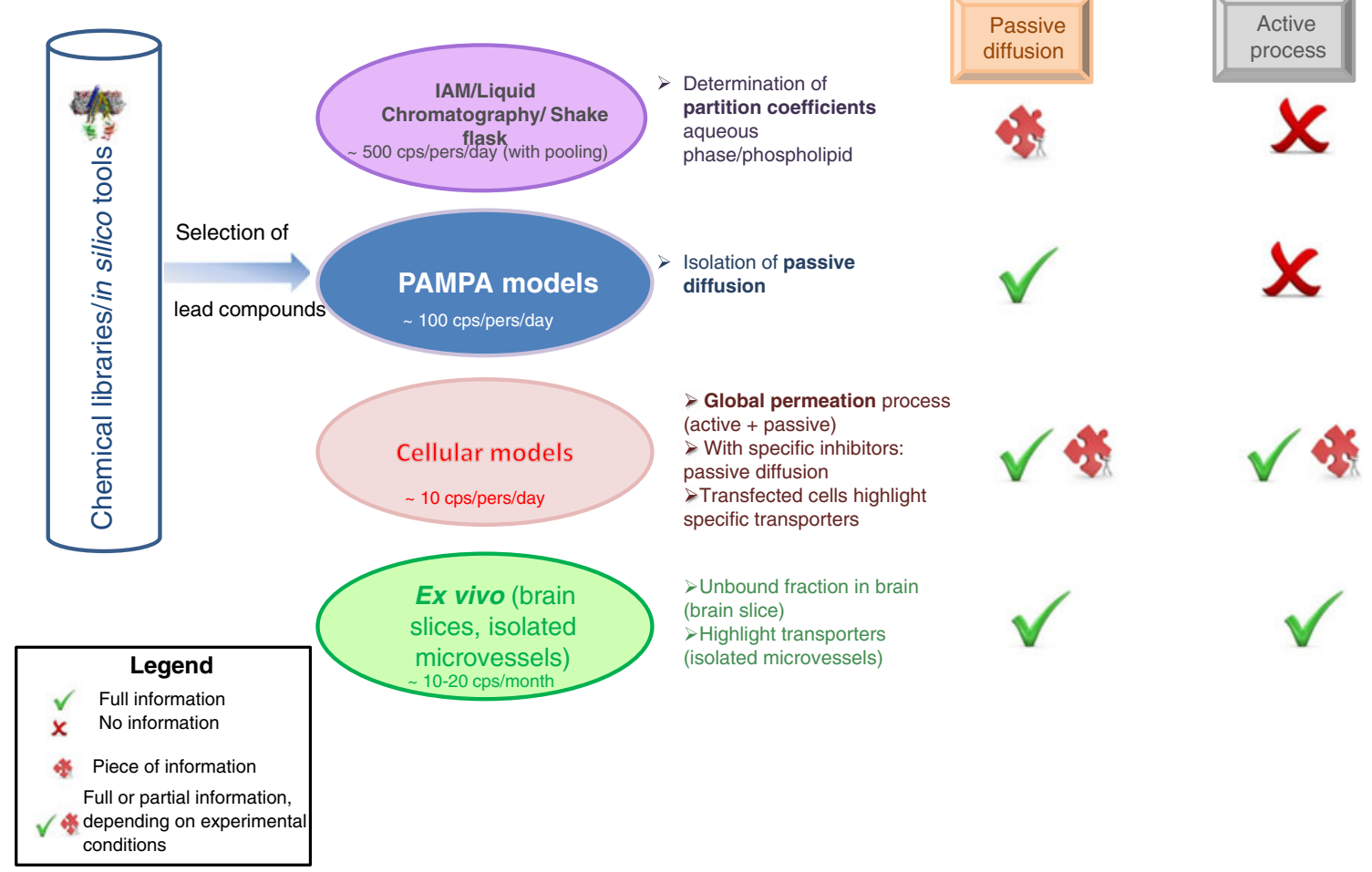

Fig. I Useful in vitro models to predict BBB permeability in early drug discovery process, and type of information generated. 
straightforward manner with the permeability equation described by Avdeef (63). The artificial membrane that was originally made of phospholipids $(56,109)$ can also be as simple as an organic solvent (110) or a mixture of solvents (111).

PAMPA is gaining interest in the early drug discovery process because it is possible to rapidly obtain the straightforward permeabilities of numerous compounds, it is cost efficient, it has high inter- and intra-laboratory reproducibility and it can target different biological membranes. The major drawback of the PAMPA technique is that it can only predict passive diffusion and is therefore unable to generate a full description of the permeability process at the BBB. It is wellknown that numerous transporters and enzymes are expressed at the BBB level, greatly modifying the pharmacokinetics of the substrates of these transporters, such as verapamil, a Pgp/ABAB1 substrate. Therefore, for these specific compounds, PAMPA generates only a portion of the information regarding passive transcellular transport. PAMPA should not be used for compound selection purposes particularly for BBB penetration, because of the numerous transporters and metabolic enzymes that are present at the BBB. P-gp/ABCB1 substrates more permeate in a PAMPA model compared to in vivo or in vitro cellular models.

Phospholipid-Based Membrane. Developed in 2003 by Li Di et al. (112), PAMPA-BBB has shown good prediction of BBB penetration for CNS classes of drugs. The drugs are described as CNS+ for compounds that have a high penetration through the BBB, CNS- for compounds that have a low permeability or are unable to penetrate the $\mathrm{BBB}$, and CNS+/ - for compounds with a medium permeability coefficient. In this assay, the artificial membrane is composed of porcine polar brain lipid extracts and the incubation last for $18 \mathrm{~h}$. A quantitative analysis correlating the permeability coefficients generated with PAMPA-BBB and in situ brain perfusion gave a poor correlation coefficient of $r^{2}=0.47(113,114)$ for a test set of 37 compounds. However, for 30 test compounds, this assay succeeded in predicting 25 compounds with the correct class of permeability, either CNS+ or GNS-. The only negative outlier was actively transported, whereas the 4 false positives were either substrates of efflux pumps or metabolised in vivo. One weak point of this assay is that it is performed under unstirred conditions, which maximises the unstirred water layer (UWL). UWL is a stagnant water layer at the two sides of the artificial membrane that has a distinct boundary with bulk water (63). This layer can highly modify the permeation of compounds, in particular hydrophobic compounds, because passage through the UWL is governed by diffusion laws. Because of the blood flow and the very small size of the cerebral capillary, the in viwo UWL is nearly null. However, this is not the case for the in vitro UWL, particularly for the unstirred in vitro assay in which the UWL can be as thick as 1.5 to $2.5 \mathrm{~mm}(115)$.
Solvent-Based PAMPA. HDG-NPOE PAMPA is a high throughput screening method that has recently been developed to predict the passive transendothelial permeability through the BBB and is currently under study (116). The innovation of this PAMPA technique is in the use of nonbiological materials for the membrane, which allows for better reproducibility. In this new PAMPA model, the artificial membrane is composed of $75 \%$ hexadecane and $25 \%$ o-nitrophenyl octyl ether and incubation lasts for $7 \mathrm{~h}$, enabling permeability determination within the working day. The experimental permeabilities determined by this new method demonstrated a good relationship with the permeabilities generated by a well-established cellular model BBCEC model from Cecchelli et al. $(27,117)\left(r^{2}=0.92\right.$; $\mathcal{N}=13)$ and the PAMPA-BBB (112) $\left(r^{2}=0.80: \mathcal{N}=14\right)$. Furthermore, a correlation was also established with an in vivo model of rat brain perfusion $(118)\left(r^{2}=0.81 ; \mathcal{N}=6\right)$ but only with a reduced number of compounds.

Compatibility of PAMPA with New Drug Delivery Strategies. In 2009, Han et al. (109) used PAMPA to determine the intestinal permeation of ginsenoside, a hydrophilic molecule with very low membrane permeation, that was incorporated into a water-in-oil microemulsion. The objective was to obtain information on the mechanism of permeability of this carrier system. The original protocol of Kansy (108) using a phospholipidic-based membrane was used. Han et al. demonstrated an increased permeation of ginsenoside due to good permeation of the water-in-oil microemulsion through the PAMPA membrane. These results were corroborated by rat everted intestinal sac studies.

In 2007, Mathot et al. (119) used the phospholipidic PAMPA developed by Kansy (120) and commercialised by pION Inc. to evaluate the passive diffusion of polymeric micelles formed from polymeric surfactants through the gastrointestinal tract. They had already shown in the Caco-2 model that the polymers were able to cross the cells but did not know the possible mechanism of passage. Analysis of the acceptor compartment demonstrated the passage of the polymeric micelles through the lipid artificial membrane with a permeability coefficient of $1.0 \times 10^{-6} \mathrm{~cm} . \mathrm{s}^{-1}$. To the best of our knowledge, no current study has evaluated the prediction of BBB permeation of these materials using the solvent-based PAMPA technique. However, the results obtained for the phospholipid-based PAMPA models for gastrointestinal tract passive transport predictions indicate that these models can be used to obtain information on the permeation of chemicals loaded in specific carriers. However, testing a new material on PAMPA is not obvious and requires particular attention regarding the reciprocal impact of carriers on the artificial membrane and vice versa. Therefore, preliminary tests must be performed before the permeability coefficients obtained from PAMPA tests can be interpreted. 


\section{Cell Culture Models}

Cellular models that predict BBB permeability are extensively used during the early drug discovery process. A large panel of cellular models exists that differ in origin, the type of expressed transporters, the tightness of the tight junctions and affiliation with a primary or immortalised cell line. These factors greatly influence the reproducibility of the permeability experiments and the capacity of these models to predict in vivo BBB permeability. Therefore, all cellular models are different and generate specific information on permeability through the BBB. Furthermore, none of the existing cellular models can fully predict the pharmacokinetic behaviour of drugs in vivo.

The main advantages of cellular models are the throughput rate, which allows for the evaluation of a reasonable number of compounds even if this rate is only moderate. Additionally, cellular models have the capacity to evaluate transport mechanisms, which depends on the type of expressed transporters and the possible evaluation of metabolism and cytotoxicity. Furthermore, pathological conditions can be investigated choosing an appropriate model (121). By contrast, homogeneity and reproducibility are difficult to obtain with cellular models, although these problems may be limited with the development of immortalised cell lines and standardised protocols.

To differentiate the wide variety of cellular models in existence since the 1970s, the following BBB parameters must be considered: the transendothelial electrical resistance (TEER), which indicates the tightness of transendothelial tight junctions and, therefore, restriction of the paracellular pathway; the endothelial permeability coefficient for paracellular markers such as sucrose, which indicates the integrity of the membrane (66); the expression of specific BBB transporters, such as the carrier-mediated transporters, including glucose transporters (GLUT1), monocarboxylic acid transporter (MCT1), large amino-acid transporters (LAT1), and cationic acid transporters (CAT); the active efflux transporters, including the ATP binding cassette (ABC) gene family or solute carrier (SLC) gene family (122); and the presence of BBB markers, such as factor VIII, $\gamma$-glutamyl transpeptidase $(\gamma$-GT), alkaline phosphatase (ALP) and monoamine oxidase (MAO) (123). Because the in vivo TEER of brain microvessels is approximately $1,000-2,000 \Omega \cdot \mathrm{cm}^{2}(124,125)$ and the permeation of sucrose can be as low as $0.03 \times 10^{-6} \mathrm{~cm} . \mathrm{s}^{-1}$ (126), the ideal cellular model should provide values as close as possible to the known values for these parameters.

Primary Cultures. Cell biology research for the development of in vitro models of the human BBB began with primary bovine $(40,127-137)$ and porcine (138-142) cultures (Table I) because the brain size of these animals is large; leading to a high yield of cells per brain. However, rat (143-145), murine (146,147) and human (148-152) cell culture systems have also been developed. Compared to porcine or bovine cells, rat and mouse endothelial cells generate models with fewer BBB characteristics, such as a TEER value between 9 and $150 \Omega . \mathrm{cm}^{2}$ and a $\mathrm{P}_{\mathrm{e}}$ (sucrose) of approximately $7.5 \times 10^{-6} \mathrm{~cm} \cdot \mathrm{s}^{-1}$ (Table I). Therefore, mouse brain endothelial cells are difficult to culture and lead to poor development of the endothelium (67). Additionally, because the number of cells per brain is limited, the batches of cells are always different even when the same protocol is used for extracting and seeding cells. This variability causes reproducibility issues because the cells used for permeability determinations are not the same from one day to the next. This is one reason why researchers have very little interest in using mouse primary cells for BBB permeability studies even if the best murine models can compete with some of the bovine models $(144,153)$.

Bovine endothelial cells were the first in vitro BBB model and were developed by Bowman et al. as soon as 1983 (130). However, one of the primary bovine models expressing sufficient TEER for the prediction of BBB penetration was developed by Zenker et al. in 2003 (154). In this model, the TEER value reached $1,350 \Omega . \mathrm{cm}^{2}$, but values this high were rare and were dependent on the batch of cells. Furthermore, no paracellular permeability verification was performed, which makes an appropriate discussion of this model difficult. In general, the average TEER value generated with primary bovine endothelial cells is $150-200 \Omega . \mathrm{cm}^{2}$, which is far from the in vivo TEER value of $1,000 \Omega . \mathrm{cm}^{2}$ (40,127-137).

Porcine models display the best barrier properties (Table I). These models exhibit high TEER values ranging from 70 to $1,800 \Omega . \mathrm{cm}^{2}$ depending on the culture conditions and medium supplementation. Porcine models also have a low paracellular permeation of sucrose, with values ranging between 0.2 and $25 \times 10^{-6} \mathrm{~cm} \cdot \mathrm{s}^{-1}(138-142,155-162)$. Moreover, specific transporters, such as GLUT-1 or acetylated LDL, and brain enzymes, such as the $\gamma$-GT or ALP, display efficient metabolic activity (142) (Table I). The most efficient cellular model of the BBB was developed by Franke et al. $(159,163,164)$ who grew primary porcine brain microcapillary endothelial cells in serum-free medium containing hydrocortisone. The result of this treatment was a monolayer of endothelial cells with very tight junctions, TEER values reaching $1,500 \Omega . \mathrm{cm}^{2}$ with an average of $700 \pm 100 \Omega . \mathrm{cm}^{2}$, and a sucrose permeation as low as $0.3 \times 10^{-7} \mathrm{~cm} \cdot \mathrm{s}^{-1}$. Further evaluations indicated that this model expressed several ATP-binding cassette $(\mathrm{ABC})$ transporters, nutrient transporters and specific BBB receptors (165). However, this model has not been used for any further permeability determinations. 


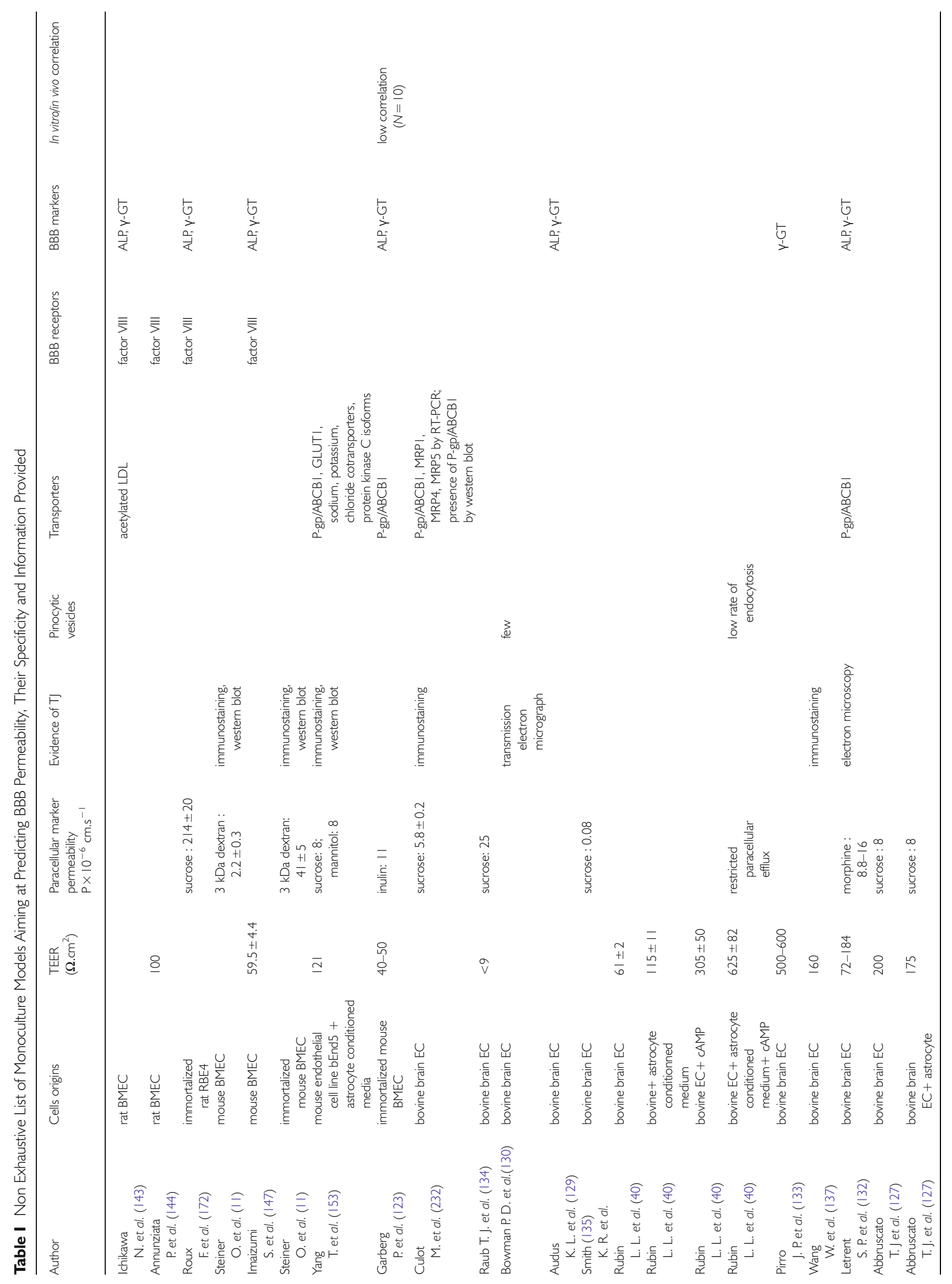




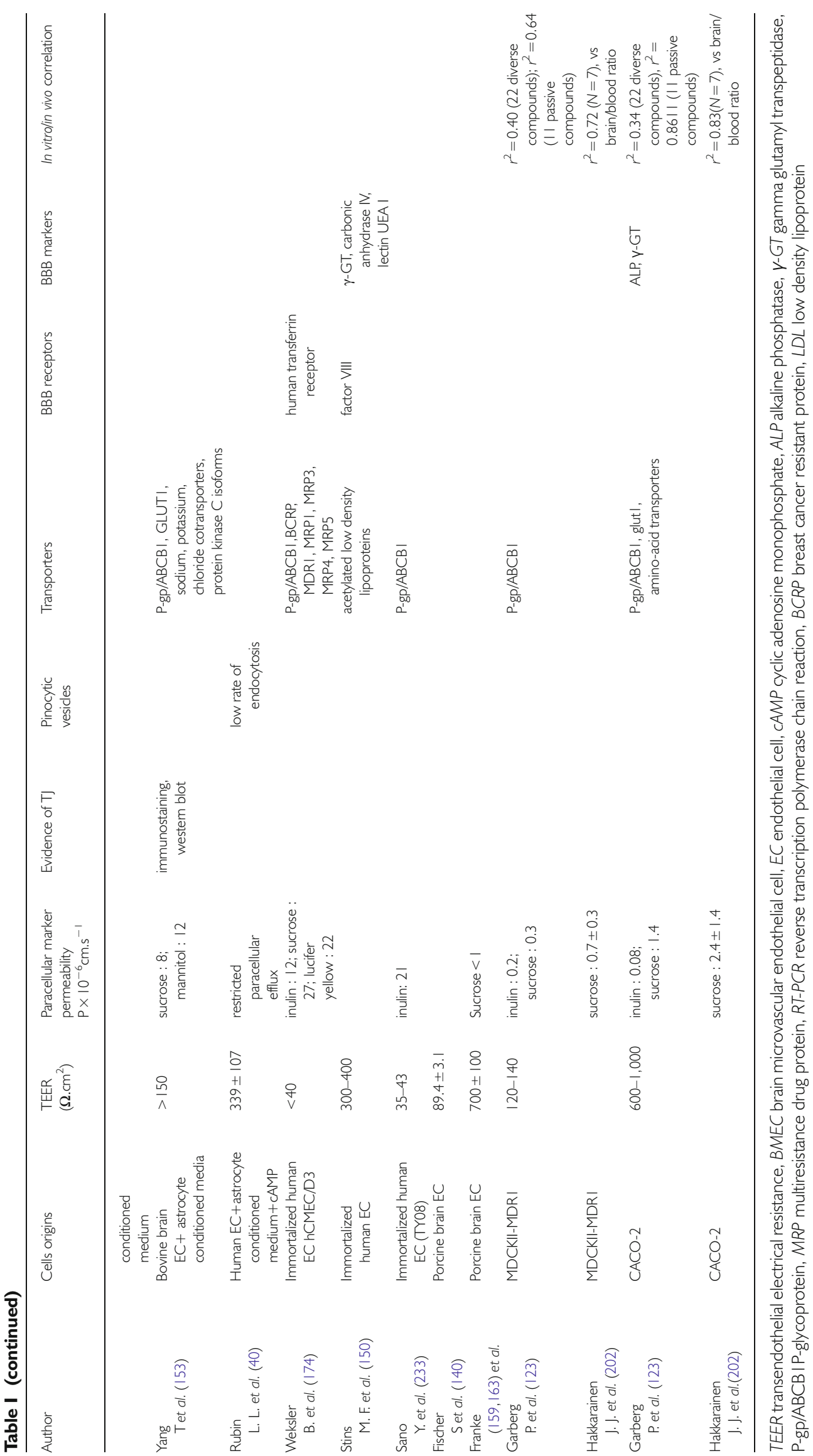


Human brain cells are the gold standard for a human BBB in vitro model. However, for ethical reasons, the availability of this type of cell is very limited. The cells are generally obtained from biopsies of epileptic patients, and the number of cells obtained is very low. Rubin et al. and Bernas et al. developed primary human endothelial cell models with TEER values of $339 \pm 107 \Omega . \mathrm{cm}^{2}$ and $>1,000 \Omega . \mathrm{cm}^{2}$, respectively $(40,166)$. No paracellular permeability was mentioned in these models, but the model developed by Bernas et al. was used in several studies to evaluate the effect of chemicals, such as cannabinoid receptor agonists, on the barrier function of BBB (167). Studies of these human models are limited and have instead focused on the generation of immortalised human cell lines, which should decrease the inter-individual, race, age and gender variations and increase the quality and reproducibility of the results obtained with human models.

Primary cell cultures may provide interesting information on human BBB permeability, but these models and culture conditions are not straightforward. Homogeneity and reproducibility of these models is not guaranteed because an animal brain cannot generate an infinite number of identical cells. Therefore, the variability of these models is due to inter-laboratory and inter-individual factors, among others, and leads to large standard deviations. Finally, primary monocultures of brain endothelial cells were shown to rapidly lose their BBB properties, including tight junctions and specific transporters (168).

Immortalised Cell Lines. To limit the drawbacks related to the handling of primary cells, researchers have immortalised their cultures to make cell lines. Immortalisation is generally achieved with either gene or virus transfection (148,169-171), such as the SV40 large T-gene antigen (67) or the E1A adenovirus gene (172) in the RBE4 model.

Few monoculture models of immortalised cell lines have been developed (Table I), however, bovine (173), human (148,150,174-181) mouse (182,183) and rat (172,183-188) endothelial cell lines have been established and tested for BBB properties. The model with the best BBB properties is a human brain endothelial cell line (150), with TEER values ranging from 300 to $400 \Omega . \mathrm{cm}^{2}$; however, no sucrose permeation has been achieved, but inulin transport studies show low paracellular permeation. In 2005, Weksler et al. developed a model based in human cerebral cells: the hCMEG/D3 cell line, which displayed a TEER value below $40 \Omega . \mathrm{cm}^{2}$ and a sucrose permeation of $27.10^{-6} \mathrm{~cm} . \mathrm{s}^{-1}$ $(174,189)$. Furthermore, many drug transporters, including most of the ABCB, ABCC and ABCG families found in the human BBB in vivo have been detected in the hCMEC/D3 cell line. Because of the existing BBB properties and its human origin, the hCMEC/D3 model has been used for many kinetic, pharmacological and permeability studies (190-193).
In order to understand the predictive ability of primary cells and immortalized cell line, Steiner et al. (11) compared primary mouse brain microvascular endothelial cells with immortalised mouse brain endothelial cell lines and determined that the two types of endothelial cells exhibited different cytoskeletal morphologies. Moreover, the protein occludin, which plays a role in tight junction formation, was localised in the primary endothelial cells but not in the cell line, indicating a divergence in the junctional organisation. This deviation leads to tighter junctions in the primary endothelial cells compared to the immortalised endothelial cells. Therefore, monocultures of immortalised cells are of limited interest for the prediction of BBB permeability, except the immortalised cell culture models derived from human cell lines.

Cocultures. Following the development of a variety of monoculture models and the determination that cerebral endothelial cells alone, whatever their origin, do not express the appropriate $\mathrm{BBB}$ properties and also lose their specific characteristics when isolated from their environment $(27,145)$, cocultures became attractive models. In the human brain, there is constant communication between endothelial cells and other types of cerebral cells comprising the neurovascular unit, such as astrocytes, pericytes, neuroglia, and neurons $(60,194)$. The action of surrounding cerebral cells on endothelial cells creates $\mathrm{BBB}$ properties and induces the production of junctional proteins and the expression of all the enzymes and transporters at the $\mathrm{BBB}(8,9,14,19,67,71,195)$. Moreover, it was shown that astrocytes were able to reinduce BBB properties (196).

Megard et al. (152) noted several interesting observations in their research on human brain endothelial cells cocultured with human astrocytes.

The resulting coculture exhibited specific barrier properties, such as a TEER value of $260 \pm 130 \Omega . \mathrm{cm}^{2}$ (endothelial cells alone: $61 \pm 2 \Omega . \mathrm{cm}^{2}$ and astrocytes alone: $\left.37 \pm 5 \Omega . \mathrm{cm}^{2}\right)$ and a sucrose permeation of $17 \pm 3 \cdot 10^{-6} \mathrm{~cm} . \mathrm{s}^{-1}$. To validate this BBB model, the authors selected the lipophilicity of a compound as a good indicator of BBB permeability. They demonstrated a good relationship between the in vitro $\mathrm{BBB}$ permeability of this model that was corrected with the molecular weight and the partition coefficients $\left(r^{2}=0.88\right)$. Using flow cytometry and PCR, they showed that their model expressed P-gp/ABCBl mRNA. A permeability determination with known P-gp/ABCB1 substrates, such as vincristine, verapamil or vinblastine, revealed a higher permeability from the basal to the apical compartments than from the apical to the basal compartments, indicating an efficient efflux process. These results underline the beneficial effect of cocultures on the expression of specific BBB properties in vitro models. The upregulation of $\mathrm{P}-\mathrm{gp} / \mathrm{ABCB} 1$ and the higher TEER value in cocultures compared to monocultures were also observed in several other studies $(9,154,184,195,197,198)$ (Table II). 


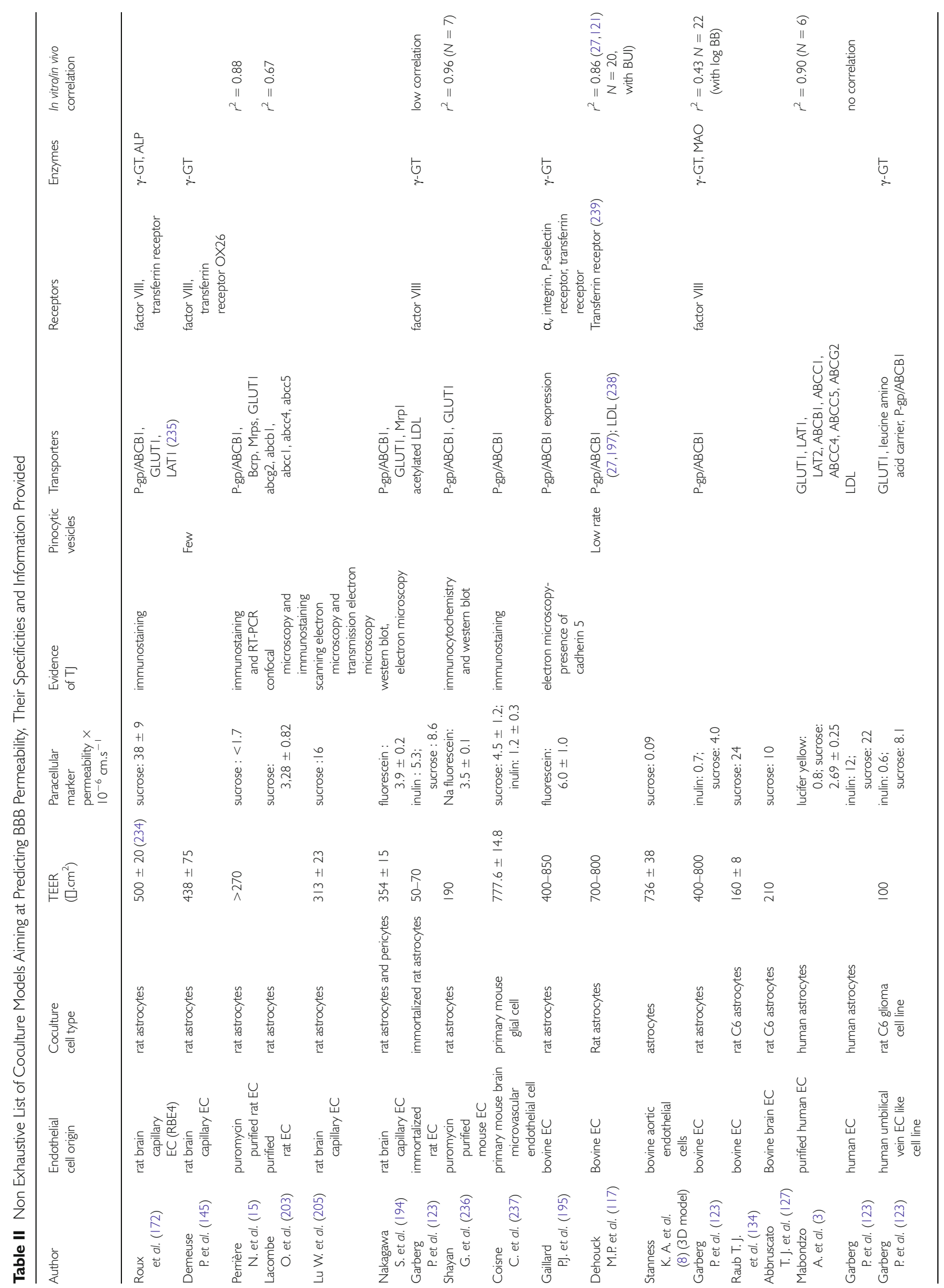




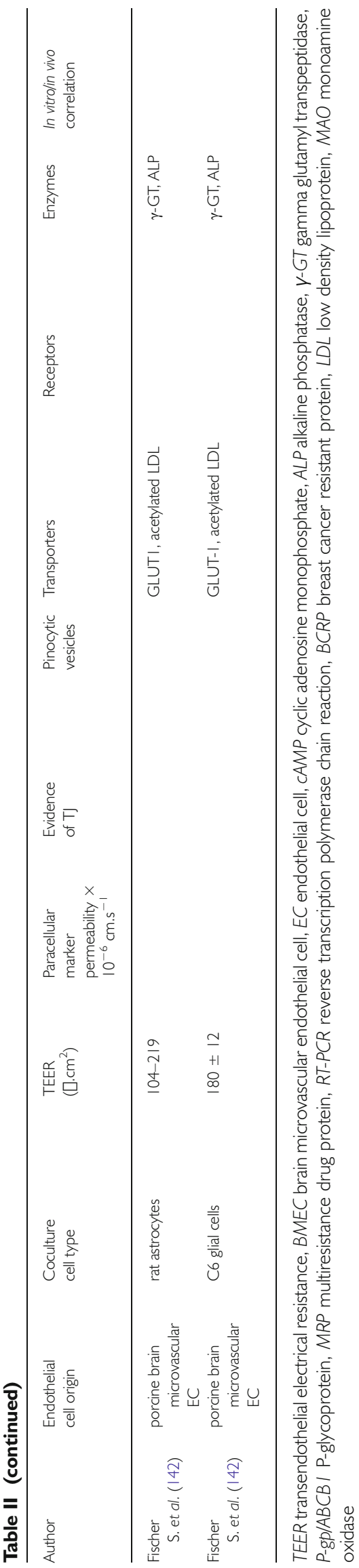

These cocultures can be established with either primary cells or cell lines. As indicated in the review by Deli et al. (66), many different cocultures have been developed but are usually established with endothelial cells and astrocytes from various animals. When the BBB properties of these cocultures were compared to the barrier properties of the corresponding endothelial monoculture, the resulting TEER values were generally improved, whereas the permeation of a paracellular tracer was decreased. Consequently, the expression of tight junction proteins is upregulated under coculture conditions, resulting in an improved in vitro $\mathrm{BBB}$ model (197).

To determine the reason why BBB properties are reinduced when endothelial cells are cocultured with astrocytes, Bénistant et al. (168) evaluated the fatty acid composition of bovine brain capillary endothelial cells either monocultured or cocultured with rat astrocytes. They found that the phospholipid profiles of the endothelial cells were clearly different between the two culture conditions. The most significant differences were observed for palmitic acid, which was $13 \%$ of the total phospholipid proportion in the monoculture vs. $20 \%$ in the coculture, and for linoleic acid, which was $18 \%$ in the monoculture vs. $10 \%$ in the coculture. Therefore, these results indicated that the presence of astrocytes when culturing endothelial cells can modify the fatty acid composition of brain endothelial cells.

In 2009, Nakagawa et al. (194) established a coculture model with three different types of cerebral cells, endothelial cells, pericytes and astrocytes, to provide a more realistic representation of the in vivo BBB. The pericytes were shown to have a similar positive influence as astrocytes on the tightness of the tight junctions (199). The TEER value of this triple coculture reached $400 \Omega . \mathrm{cm}^{2}$, with a permeation of $3 \times 10^{-6} \mathrm{~cm} . \mathrm{s}^{-1}$ for the non-permeant dye fluorescein. Moreover, specific BBB transporters, such as P-gp/ABCB1, glucose-transporter (GLUT1) and ABCG1, were expressed in the brain endothelial cells (Table II).

The BBB model displaying the best barrier features was developed by Dehouck et al. $(27,39,121,197,200)$ and was called the bovine brain capillary endothelial cells model (BBCEC). This model, consisting of primary bovine endothelial cells cultured on one side of the filter and rat glial cells on the other side of the filter, exhibits high TEER values due to the presence of complex tight junctions. The TEER values range between 700 and $800 \Omega . \mathrm{cm}^{2}$ (13), and the BBCEC model displays a low sucrose permeation between 5.4 and $32 \times 10^{-6} \mathrm{~cm} . \mathrm{s}^{-1}$, a low rate of pinocytosis, the presence of $\mathrm{P}$ $\mathrm{gp} / \mathrm{ABCB} 1$ and metabolic enzymes, such as $\gamma$-GT, MAO, and the occurrence of LDL and transferrin receptors (27). This combination of characteristics leads to interesting BBB properties.

When correlating in vitro $\mathrm{BBB}$ data, which are corrected by the molecular weight and a logarithmic function, with the 
corresponding BUI or in vivo BBB permeability, both of which are also corrected, excellent relationships were observed $\left(r^{2}=0.86\right)(121)$.

In conclusion, with regard to cellular models consisting of cerebral cells, primary cell cocultures generate the best models, although the reproducibility may not be optimal. The upregulation of tight junction proteins under coculture conditions allows for increased TEER values and decreased paracellular transport, which are characteristics of the BBB. The gold standard model would be a coculture of primary human cells, but this requires a constant renewal of the donor brain tissue, which causes ethical concerns.

\section{Cell Lines of Non-Cerebral Origin}

The Madin-Darby Canine Kidney Cell line (MDCK). MDCK cells are cells of non-cerebral origin that are relatively easy to grow and can be transfected with specific gene transporters, particularly the MDRl gene, which codes for polarised expression of P-gp/ABCBl (71). These transfected MDCK cells can then be used for the MDR1-MDCK (I or II) assay. MDCK cells can generate TEER values as high as 1,800$2,200 \Omega \cdot \mathrm{cm}^{2}$ (201), indicating the existence of robust barrier properties with high expression of tight junctional proteins. Moreover, the in vitro-in vivo correlation obtained with this model is better than some of the existing in vitro models with cerebral cells, with $r^{2}=0.64$ (123) or 0.72 (202) when passive compounds are selected for the correlation, depending on authors. However, in vitro/in vivo correlations with a diverse set of compounds (including compounds being actively transported or effluxed at the BBB) do not exhibit a significant correlation $\left(r^{2}=0.40\right)(123)$. The greatest limitation of these cells is the absence of transporter proteins other than Pgp/ABCB1 and their different morphology compared to endothelial cells because MDCK cells are epithelial cells $(71,203)$. Moreover, these cells are derived from dog kidney cells (201). However, transfection of the MDR 1 gene allows for the determination of $\mathrm{P}$-gp/ABCB1 substrates by measuring the permeability on both sides of the membrane. Another study conducted by Di Li et al. (114) did not generate an in vitro-in vivo correlation comparing the in vitro MDR1MDCK permeation of a very diverse set of compounds with permeations obtained from in situ brain perfusion $\left(r^{2}=0.007\right.$ (114)). This absence of correlation was most likely due to saturation of the $\mathrm{P}-\mathrm{gp} / \mathrm{ABCB} 1$ in vivo. The concentrations utilised for the in situ brain perfusion study were very high compared to the Michaelis-Menten constants of the compounds. These high concentrations lead to saturation of the efflux transport and use of the predominantly passive diffusion pathway, which overestimates the permeability in vitro. Therefore, attention should be paid to the experimental conditions when performing permeability assay with saturable transport. Moreover, differences in membrane characteristics, such as epithelial kidney cells for the MDR1-MDCK assay and cerebral endothelial cells for the in situ brain perfusion study, lead to a significant discrepancy in the predicted BBB permeability. Moreover, the phospholipid composition of both membranes is fundamentally different, with a higher proportion of cholesterol in the cerebral membrane than the MDCK cells. This composition leads to an increased fluidity of MDCK cells, which facilitates passive permeability in this model.

Caco-2 Cells. Caco-2 cells are epithelial cells derived from a human colon carcinoma and are extensively used in the pharmaceutical industry to predict oral absorption through the intestinal epithelium. Moreover, the Caco-2 model is also used to predict BBB transport, even though the gastrointestinal tract is fundamentally different from the BBB, but as in vitro $\mathrm{BBB}$ models have evolved, the in vivo permeability predicted by the Caco-2 model became less and less useful $(121,123,202)$. compared to other models. However, the Caco-2 assay remains an efficient method of identifying substrates of the P-gp/ABCBl transporter from a set of test compounds because of the overexpression of P-gp/ABCB1 in cancer cells. More recently, Ball et al. (204) developed a physiologically based pharmacokinetics model to predict the fraction of unbound drug reaching the brain. They succeeded in generating an in vitro model that faithfully fits the in vivo unbound brain concentration of morphine, which is effluxed at the BBB, and oxycodone, which is taken up at the BBB. The $\mathrm{K}_{\mathrm{p} \text {,uu }}$ was determined in Caco-2 cells expressing the $\mathrm{P}$ gp/ABCB1 efflux transporters for morphine and in TRBBB13 cells, which enable active uptake, for oxycodone. Both resulting distributions were corrected by a relative activity factor, which was estimated by a comparison between the in vitro model predictions and the in vivo data in rats.

\section{Adaptation of BBB Cell Models to New Delivery Strategies}

Some models were used to obtain information on nanocarrier transport across the BBB.

Nanoparticles. In 2006, the transcytosis of polyethylene glycol-polylactide (PEG-PLA) nanoparticles across the BBB was evaluated by Lu et al. using a rat syngeneic coculture of brain capillary endothelial cells and astrocytes (205). The fluorescent compound 6-coumarin was incorporated inside these nanoparticles with a final size of $102.4 \pm 6.8 \mathrm{~nm}$. After transport study of the coumarin-loaded PEG-PLA nanoparticles across the coculture, a permeation of $4.8 \times 10^{-6} \mathrm{~cm} . \mathrm{s}^{-1}$ was obtained. However, the permeation of the paracellular marker sucrose was higher than the permeation of the nanoparticles. Therefore, either a 
paracellular route or a transcytosis process may have occurred in this in vitro model.

Ragnaill et al. (206) later described the transport of $50 \mathrm{~nm}$ silicium dioxide nanoparticles through the in vitro hCMEC/D3 BBB model $(174,189)$. They succeeded in showing that nanoparticles were effectively taken up by the cells with the membrane enveloping the nanoparticles. Moreover, they also observed the nanoparticles in both the endosomes and lysosomes and some on the basolateral side of the membrane. Therefore, they suggested that the silicium dioxide nanoparticles were endocytosed and that an exocytosis process also occurred.

Liposomes. The hCMEC/D3 cell line was also used to study the BBB penetration of an immunoliposome decorated with OX-26, an anti-transferrin monoclonal antibody (193). The objective of the study was to target the transferrin-receptor for transport of the immunoliposome by a receptor-mediated transcytosis process. The mean diameter of the immunoliposomes was assessed with dynamic light scattering and was less than $200 \mathrm{~nm}$. They demonstrated that the immunoliposomes were transported through the endothelial monolayer by receptor-mediated endocytosis.

In vitro cellular models can therefore be used for the permeability determination of more complex formulations, such as nanocarriers. However, adaptation of the model may not be straightforward because of the potential cell toxicity of the carriers, and a full assessment of the validity of the models is required before a discussion of the results, but promising data regarding the distribution of nanocarriers are emerging.

\section{Transport Across Isolated Brain Microvessels}

Isolated brain microvessels are generally used to evaluate the gene expression of specific transporters at the BBB (207), but permeability experiments may also be conducted to identify specific transporters. Fluorescent probes are tested in the presence or absence of known substrates of the transporters. A variation in the permeability indicates the presence of the specific transporter that is being assessed (208,209). Miller et al. used confocal microscopy to detect fluorescent xenobiotics, such as daunomycin and fluorescein labeled dextrans, within the lumen of isolated brain microvessels (208). They succeeded in demonstrating a concentrative, specific and energy-driven transport process, indicating the expression of specific active transporters in isolated brain capillaries. Studies with specific substrates and immunostaining indicated that the active process was initiated by P-gp/ABCB1 and Mrps. The P-gp expression in isolated brain capillaries was corroborated by the studies of Durk et al. (209).

Transport across freshly isolated brain microvessels is a good alternative to cell culture because it is less time consuming; however, isolation of the brain microvessels requires much skill and very clean manipulations to obtain microvessels that are extremely pure. Moreover, reproducibility issues may be more important in this model than for cellular models because fresh microvessels must be freshly prepared for each experiment.

\section{In Vivo Models}

In vivo models are the best models available to predict human in vivo permeabilities because of the combination of all biological aspects in the same model, such as physiological barriers, transporters, and metabolic pathways. However, these models are expensive, time-consuming, require the mastering of animal-based assays and often necessitate radiolabelled compounds. These factors ensure that in vivo models are used during the later stages of the drug discovery process, just prior to clinical investigations, for a limited number of lead compounds. Different in vivo models are available, which allows for determination of the permeation of the molecules tested and in particular the logarithm of the BBB permeability-surface area $(\log$ PS) or the logarithm of the brain to plasma ratio $(\log \mathrm{BB})$ (Table III). These models include in situ brain perfusion, single carotid injection (brain uptake index; BUI), intravenous injection and intracerebral microdialysis (71). The log PS is considered the most relevant indicator of BBB permeability because it measures the clearance of a drug from the blood to the brain across the BBB (210) and is not altered by either metabolism or protein binding (114). The log PS is determined from the $\mathrm{K}_{\mathrm{in}}$, which is the clearance out of the brain. This determination better reflects BBB permeability..

Determination of the $\log$ BB requires several time point measurements, which requires animals a t each time point and is costly. Moreover, several factors, such as metabolism and binding, interfere with brain penetration in the $\log \mathrm{BB}$ determination; therefore, $\log \mathrm{BB}$ is not an accurate measurement of BBB permeability.

\section{The Intravenous Administration Technique}

Intravenous administration is one of the less invasive and most physiological methods of determining in vivo permeability. In this technique, the buffer containing radiolabelled solutes is injected inside a cannulated femoral vein or in the tail vein of the rat. The plasma concentration of the products is monitored for $10 \mathrm{~s}$ to several hours over various time points. The pharmacokinetic parameter obtained is the area under the curve of the drug concentration in the blood between time 0 and the time of the decapitation (211). Therefore, the measured permeability will include the effective permeability, which is influenced by protein binding and metabolism. This technique has numerous advantages, such 
Table III Summary of the In Vivo Techniques in Late Drug Discovery Research

\begin{tabular}{|c|c|c|}
\hline In vivo techniques & Characteristics & Experimental data \\
\hline Brain/plasma ratio & $\begin{array}{l}\text { Study of low to rapid penetrating compounds; } \\
\text { choice of variable exposure times; possible } \\
\text { metabolism, protein binding and active transport. }\end{array}$ & $\begin{array}{l}\text { A partition coefficient between plasma (or blood) } \\
\text { and brain is generated. Be careful to misleading } \\
\text { caused by protein binding. }\end{array}$ \\
\hline Brain uptake index & $\begin{array}{l}\text { Study of moderate to rapid penetrating compounds; } \\
\text { fast brain exposure ( } 5 \text { to I } 5 \text { s between the } \\
\text { injection and the sacrifice of the animal); no } \\
\text { metabolism, no protein binding, no efflux transport. }\end{array}$ & $\begin{array}{l}\log \text { PS are generated. The extremely fast brain } \\
\text { exposure time leads to sensitivity problems, } \\
\text { due to very low concentration in the brain. }\end{array}$ \\
\hline In situ brain perfusion & $\begin{array}{l}\text { Suitable for low to rapid penetrating compounds; fast } \\
\text { to long exposure times ( } 5 \text { s to I h); no metabolism, } \\
\text { no protein binding, possible transport. }\end{array}$ & $\begin{array}{l}\text { Data similar as Brain uptake index is generated. } \\
\text { Sensitivity is much higher, thanks to a possible } \\
\text { long brain exposure time. }\end{array}$ \\
\hline Intravenous administration technique & $\begin{array}{l}\text { Study of low to rapid penetrating compounds; } \\
\text { monitoring of the plasma concentration; existence } \\
\text { of in vivo metabolism, protein binding and transport. }\end{array}$ & $\begin{array}{l}\text { A whole pharmacokinetics profile is generated, } \\
\text { on an intact BBB. This is the less ethically invasive } \\
\text { and the most physiological method. }\end{array}$ \\
\hline \multirow[t]{2}{*}{ Intracerebral microdialysis } & \multirow{2}{*}{$\begin{array}{l}\text { More appropriate for medium permeant compounds. } \\
\text { Drug monitoring of the unbound drug fraction after } \\
\text { the choice of the mode of administration; existence } \\
\text { of in vivo metabolism, protein binding and transport. }\end{array}$} & $\begin{array}{l}\text { A whole pharmacokinetics profile is generated, but } \\
\text { BBB can be damaged due to surgery. }\end{array}$ \\
\hline & & $\begin{array}{l}\text { Monitoring is made on the same animal: decrease } \\
\text { the number of experimental animals, no deviation } \\
\text { due to variation in the origin, age, gender, weight } \\
\text { of the animal. }\end{array}$ \\
\hline Imaging & $\begin{array}{l}\text { Visualisation of the distribution in the body. Appropriate } \\
\text { for medium to rapid penetrating compounds. }\end{array}$ & $\begin{array}{l}\text { Non-invasive technique, which can be employed } \\
\text { in humans. Existence of sensitivity issues, require } \\
\text { expensive equipment. }\end{array}$ \\
\hline
\end{tabular}

as the BBB remaining undisturbed and all transporters, enzymes and junctional proteins remaining intact, which enables metabolism. An entire pharmacokinetics profile can therefore be obtained. Moreover, because the evaluation can be performed for an extended period of time, both the plasma and brain pharmacokinetics can be determined. However, the study of specific influx transport is not possible with this intravenous administration technique.

\section{The Brain/Plasma Ratio}

The brain/plasma ratio, established by Ohno et al. (212), resulted in determination of the blood-brain distribution coefficient $(\mathrm{BB})$, which is defined as the ratio between the concentration of the compound in the brain and in plasma. Therefore, this approach may be misleading because the partition parameter that is obtained is dependent on the affinity of the tested drug for circulating proteins in the blood stream (213). This method provides determination of the drug partition between the plasma and brain but does not provide a pharmacokinetic profile. Determination of the brain/plasma ratio can be performed either at steady state or at different time points and requires sacrificing the animal and determining the concentration of the unbound drug in both the brain homogenate and plasma.

A brain/plasma ratio $\geq 1$ indicates that a compound is able to cross the $\mathrm{BBB}$, whereas a brain/plasma ratio $<1$ reveals a poor distribution of the compound (213). However, due to plasma protein binding, a brain/plasma ratio $<1$ may also indicate a high affinity for circulating plasma proteins or an affinity for efflux proteins, both of which limit permeation of the compound through the barrier. Therefore, interpretation of the brain/plasma ratio must be performed cautiously.

Young et al. (214) used the brain/plasma ratio to design and select a CNS-active $\mathrm{H}_{2}$ histamine receptor antagonist. More recently, Rohanova et al. used the brain/plasma ratio to study the brain penetration of a new illegal drug pmethoxymethamphetamine and its metabolites to better understand both the mode of action andas the toxicity profile of these new drugs (215).

\section{The Unbound Brain/Plasma Ratio: $K_{p, u u}$}

To correct the errors that may be introduced by measurement of the brain/plasma ratio, a recent tendency consist in determining the unbound brain to plasma ratio $\left(\mathrm{K}_{\mathrm{p}, \mathrm{uu}}\right)$. This parameter may be obtained directly by intracerebral microdialysis or with a combination of in vivo and ex vivo techniques. The last experiment is achieved measuring the quantity of drug that has reached the entire brain in vivo combined with an estimation of the unbound brain volume of distribution with ex vivo techniques such as the brain slice uptake experiment. The determination of $\mathrm{K}_{\mathrm{p} \text {,uu }}$ provides a better indication of the distribution of the active form of the drug. A $\mathrm{K}_{\mathrm{p} \text {,uu }}$ that is greater than unity indicates the presence of an active uptake process, whereas a $\mathrm{K}_{\mathrm{p} \text {,uu }}$ less than unity indicates the presence of an efflux process. A $\mathrm{K}_{\mathrm{p}, \mathrm{uu}}$ near one indicates that the predominant pathway through the $\mathrm{BBB}$ is a passive diffusion process (216). 
Intracerebral Microdialysis. Microdialysis allows for determination of the cerebral extracellular free drug concentration over a period of time with calculation of the $\mathrm{K}_{\mathrm{p}, \mathrm{uu}}$. This free drug fraction represents the active form of the drug. Microdialysis requires the implantation of a dialysis probe in a selected area of the brain of the animal. This microdialysis probe consists of a semipermeable membrane that is continuously infused with physiological solution (217). Therefore, the compounds that are able to permeate through the membrane will diffuse according to the concentration gradient. This procedure does not require a specific mode of administration, and the permeation of the tested compound can be monitored after oral, intravenous, subcutaneous or infusion administration. Therefore, any drug entering the brain, which is always the unbound fraction of the drug, will be monitored over time in the extracellular fluid of the same animal (218) using HPLC, UHPLC or capillary electrophoresis. This technique requires a reduced number of animals for the pharmacokinetics determination compared to other techniques (71). Moreover, because the same animal is monitored, there is no deviation due to variation in the population, gender or age of the animal. However, implantation of the dialysis system may locally disrupt the $\mathrm{BBB}$, leading to a possible misinterpretation of the results. Moreover, highly lipophilic compounds can be adsorbed onto the probe, leading to mass-balance errors. This technique is more appropriate for moderately permeable compounds.

Intracerebral microdialysis was used by Gupta et al. (219) to compare the BBB transport and CNS distribution of two cetirizine enantiomers, the $\mathrm{R}$ and the $\mathrm{S}$ forms, to evaluate the stereoselectivity that occurs at the BBB. They compared the $\mathrm{K}_{\mathrm{p}}$ (total brain to total plasma concentrations), $\mathrm{K}_{\mathrm{p}, \mathrm{u}}$ (total brain to unbound plasma concentrations) and $\mathrm{K}_{\mathrm{p} \text {,uu }}$ (unbound brain to plasma concentrations) for both enantiomers. Whereas the $\mathrm{K}_{\mathrm{p}}$ value could have led to the interpretation that brain penetration was stereoselective for both isomers $\left(\mathrm{K}_{\mathrm{p}}=0.22\right.$ for S-cetirizine and 0.04 for $\mathrm{R}$-cetirizine), the $\mathrm{K}_{\mathrm{p}, \mathrm{u}}$ (0.44 for S-cetirizine and 0.22 for $\mathrm{R}$-cetirizine) indicates that plasma protein binding greatly influences the biodistribution of both forms of the antihistamine. The unbound fraction was found to be 0.50 for S-cetirizine but only 0.15 for R-cetirizine. When considering both the plasma protein binding and brain tissue binding, they discovered that the $\mathrm{K}_{\mathrm{p} \text {,uu }}$ values were similar for both enantiomers $\left(\mathrm{K}_{\mathrm{p} \text {,uu }}=0.17\right.$ for $\mathrm{S}$ cetirizine and 0.14 for $\mathrm{R}$-cetirizine). These similar values indicate that both enantiomers are effluxed at the BBB $\left(\mathrm{K}_{\mathrm{p} \text {,uu }}<1\right)$ and that no significant difference occurs in their transport. The information generated by these in vivo methodologies that are able to distinguish between the active (unbound fraction) and inactive forms of the drugs are therefore able to reliably determine the biodistribution profile of a drug at the BBB.
The In Vitro Brain Slice Uptake Experiment Combined with the In Vivo $K_{p}$. Determination of the entire concentration of a drug in the brain in vivo, combined with the volume of distribution of the unbound drug determined by an in vitro brain slice uptake experiment, allows for calculation of the unbound brain to plasma concentration ratio $\mathrm{K}_{\mathrm{p} \text {,uu }}(220,221)$. In the brain slice uptake experiment, the brain of a sacrificed animal is removed and immersed in ice-cold oxygenated $\mathrm{pH} 7.4$ buffer (221). Brain slices $(300 \mu \mathrm{m})$ of striatal areas are cut with a microslicer and preincubated with an extracellular fluid buffer before addition of the drug. At specific incubation times, the brain slices are removed from the solution of buffer containing the drug, dried, weighed and homogenised for determination of the amount of drug recovered in the brain slice. The main advantage of this technique is in the determination of the pharmacologically active unbound fraction of the drug in the brain. Moreover, the brain slices contain intact cerebral endothelial cells with their functional transporters as well as the same extra-to-intra-cellular $\mathrm{pH}$ gradient found in vivo (220). By contrast, the throughput of this model is limited due to the need for experimental animals and the minimum incubation time needed to reach drug equilibrium between the buffer and the brain slices, which is required to calculate $\mathrm{V}_{\mathrm{u}}$, brain $(220)$. As the incubation time to reach equilibrium increases with the $\mathrm{V}_{\mathrm{u}}$, brain and the $\mathrm{V}_{\mathrm{u}}$, brain increases with lipophilicity, the majority of compounds during the drug discovery phases require longer and longer incubation timestime, which cannot be supported by the limited life expectancy of the brain slices. Friden et al. evaluated this brain slice uptake assay to rapidly determine the unbound drug concentration in the brain (221). When they compared the results that were obtained for 15 diverse compounds with in vivo intracerebral microdialysis, they observed a reliable correlation between both techniques.

\section{The Brain Uptake Index (BUI) Technique}

The brain uptake index model is appropriate for compounds that moderately to rapidly penetrate the $\mathrm{BBB}$ and is generally performed in rats. A rapid bolus injection of $200 \mu \mathrm{l}$ buffered solution containing a known concentration of a radiolabelled reference compound and the tested drug is administered directly into the carotid artery of the rat. The brain is then removed after 5-15 s and analysed for radiolabelled contents (71) by scintillation counting. BUI allows for determination of the $\log$ PS, which is the permeability multiplied by the surface area. This technique is based on the following three hypotheses: the time between injection and decapitation is so short that no metabolism occurs before the brain is removed; the compound can diffuse from the blood to the brain; and when the compound is in the brain, it cannot go back into the blood (222). The main drawback of 
this technique is that extremely low concentrations of drug are present in the brain because of the very short analysis time, which causes sensitivity problems for compounds with low permeability. This technique is more appropriate for compounds with a high permeability through the BBB. For example, this technique has been used by Oldendorf et al., who demonstrated modulation of the transporter activity under different $\mathrm{pH}$ conditions (223).

\section{The In Situ Brain Perfusion}

In situ brain perfusion is suitable for low to high permeant compounds (43) or substrates of an endogenous transport system. This model provides the same information as the BUI but with higher sensitivity. In situ brain perfusion is performed on an artificial cerebral circuit, resulting from the ligature of some cerebral arteries and catheterisation of the external carotid artery. Therefore, the flow rate and duration of perfusion are known and can be controlled. The brain is then perfused with an oxygenated hydrogenocarbonate buffer containing a known amount of radiolabeled compound. Determination of the radioactivity at a predefined time, ranging from $5 \mathrm{~s}$ to $30 \mathrm{~min}$,) allows for the direct determination of pharmacokinetics parameters, particularly the volume of distribution and the rate of compound transfer, $\mathrm{K}_{\text {in }}(43,224)$.

Because the composition of the perfusate is controlled, in situ brain perfusion allows for the determination of PS values without considering either metabolism or plasma and brain protein binding. Only the intact form of the drug reaches the brain. This method provides information regarding the time required for the compound to cross the $\mathrm{BBB}$. Moreover, the amount of drug reaching the brain is fully controlled. Compared to the BUI, the sensitivity of in situ brain perfusion is much higher because of a longer exposition time of the brain (126). This method is particularly interesting for determination of the kinetics of saturable transport at the BBB.

In situ brain perfusion was used by Cannon et al. (225) to study the modulation of P-gp/ABCB1 activity. They found that activation of the sphingosine-1-phosphate receptor by a specific ligand such as sphingosine-1-phosphate led to a decrease in $\mathrm{P}$-gp/ABCB 1 activity. The activity returned to the basal state after the administration of sphingosine-1phosphate receptor antagonist. They concluded that this strategy could be used to increase the CNS bioavailability of P-gp substrates, such as verapamil or loperamide.

\section{The Brain Efflux Index}

The brain efflux index has been developed to determine the presence of a potential efflux pathway at the BBB when the compound is postulated to be transported from the brain to the blood. This technique is generally used to understand why a sufficiently lipophilic compound fails to penetrate the brain (211).

Briefly, the test and reference compounds are microinjected directly into the brain tissue. After a predefined time, the brain is removed and the tissues are analysed to determine the concentration of the residual compounds.

This protocol requires the use of a highly sensitive method to determine the small amounts of compounds that may be present. Moreover, the researcher must be careful during the microinjection because a rapid or careless manipulation will irreversibly damage the $\mathrm{BBB}$ and confound the resulting measured permeability. The major drawback of this technique is the sacrifice of a large number of rats at different time points.

Kakee et al. (226) used this technique to highlight the saturable efflux transport of para-aminohippuric acid at the BBB. A comparison of the apparent efflux clearance that was obtained in this study using the brain efflux index method with the apparent influx clearance obtained by BUI confirmed the selective transport of the carboxylic acid under investigation from the brain to the blood.

\section{Non-Invasive Imaging Techniques}

Non-invasive imaging techniques have been developed to qualitatively and quantitatively determine the permeation of drugs in vivo. Moreover, imaging can also be used to identify P-gp/ABCB1 inhibitors or P-gp/ABCB1 substrates (227) or to determine the BCRP activity at the BBB (228). These techniques are primarily positron emission tomography (PET), magnetic resonance imaging or magnetic resonance spectroscopy. Because these techniques are noninvasive, they can be used in humans and allow for the determination of personalised pharmacokinetics. Imaging is also used to detect BBB damages in patients suffering from a stroke, brain tumours or multiple sclerosis. However, these techniques require expensive equipment and labelled radiotracers. Sensitivity issues may be encountered, particularly with magnetic resonance imaging (126). Knight et al. used magnetic resonance imaging to localise and quantify the $\mathrm{BBB}$ opening in a rat model under ischaemic conditions after the intravenous infusion of gadoliniumdiethylenetriamine pentaacetic acid to achieve a blood concentration (229). Under normal conditions, this substance should not penetrate the brain. Other researchers, such as Serres et al., established a promising approach for the early diagnosis of brain tumors by targeting brain metastasis with iron oxide microparticles loaded with contrast agents (230). Magnetic resonance imaging allowed for the visualisation of brain metastases with 3-fold greater sensitivity than conventional tumour diagnostics. ${ }^{13} \mathrm{C}$ magnetic resonance spectroscopy was used to assess the relationship between brain and plasma concentrations of glucose in patients suffering from 
diabetes type I during a hypoglycaemichypoglycemia event (231).

Therefore, imaging is an efficient approach to determine personalised permeabilities during or after a pathological event. The main advantage of this technique is that it can be conducted in human for specific purposes and with safe drugs or dyes. Moreover, the distribution profile can be visualised, identifying the targeted regions of the brain.

\section{CONCLUSIONS}

The specific organisation of the cerebral endothelial cells forming the BBB causes multiple problems for a drug that needs to reach the central nervous system. Additionally, the $\mathrm{BBB}$ is not only a physical barrier but also a pharmacological and a metabolic barrier due to the expression of numerous transporters and the presence of a variety of enzymes. These features are the reason why attrition rate is so high for CNS drug candidates. However, the population worldwide is aging and by 2050, elderly people over the age of 65 will represent $16 \%$ of the population (43). Along with this global aging, CNS disorders, such as Alzheimer's disease, increase exponentially, whereas treatments are lacking. Thus, there is a real need to either improve GNS drug discovery or to change the CNS drug delivery strategy by using colloidal vectorisation. The second option has garnered great interest during the last few decades. Vectorisation of active CNS drugs and mRNA or peptides with carriers that are able to recognise a specific target at the BBB are no longer impossibilities.

The main questions that remain to be answered in the early drug discovery and development processes are as follows: is the chemical CNS active? Is the drug a substrate of influx or efflux transporters? Is the drug bioavailable? Is it easily metabolised? As described in this review, many tools are available to predict and/or understand the mode of transport of a new chemical entity (NCE) through the BBB. These tools include computational sciences, in vitro and in vivo models and knowledge regarding new transporters. However, it is clear that a combination of methods, even in vitro models, should provide more relevant information regarding the potential of a drug to penetrate the BBB. Each method provides specific insight into the transport condition of NCEs, and only proper knowledge of the specificities of each model will help scientists to decrease the compound attrition rate. In vivo models provide much more global information regarding the BBB permeation of NCEs than other models. However, even simple models, such as artificial membranes, should not be neglected in the discovery process. Although these models provide neither a global view nor a realistic tool for the selection of compounds, they are useful for understanding the transport mechanism. The simplicity of these models isolates de facto unique or a limited number of aspects of the entire transport process. Similarly, although some cellular models do not provide sufficient relevancy in terms of BBB prediction, particularly regarding the tightness of the intercellular junctions as evaluated by TEER measurement and/or the permeation of sucrose, they constitute an extraordinarily predictive and sometimes selective tool for medicinal chemists if the data are well interpreted.

All of these models that are used for the evaluation of BBB penetration by NCEs may also provide information regarding the penetration of colloidal vectors and other nanocarriers. Currently during the drug discovery and development processes, an increasing number of delivery systems must be tested for efficacy; but, few models have been used and validated for the screening of new formulations. Moreover, kinetic parameters of carrier degradation that influence drug release should also be taken into consideration when evaluating a new model. Therefore, existing methods to predict or characterise BBB permeability need to adapt to these new drug delivery systems in order to fully understand their mode of action.

\section{ACKNOWLEDGMENTS AND DISCLOSURES}

Authors thank Professor Eric Allémann for useful discussions.

\section{REFERENCES}

1. Kennedy T. Managing the drug discovery/development interface. Drug Discov Today. 1997;2:436-44.

2. Tsaioun K, Bottlaender M, Mabondzo A, and Alzheimer's Drug Discovery Fdn. ADDME - avoiding drug development mistakes early: central nervous system drug discovery perspective. BMC Neurol. 2009;9(supll 1): S1.

3. Mabondzo A, Bottlaender M, Guyot AG, Tsaouin K, Deverre JR, Balimane PV. Validation of in vitro cell-based human bloodbrain barrier model using clinical positron emission tomography radioligands to predict in vivo human brain penetration. Mol Pharm. 2010;7:1805-15.

4. Davson H. History of the blood-brain barrier concept. In: Neuwelt EA, editor. Implications of the blood-brain barrier and its manipulation, Basic science aspects, vol. 1. New York: Plenum Publishing Corp; 1989. p. 27-52.

5. Ehrlich P. Das sauerstoff-bedürfniss des organismus: eine farbenanalytische studie, A. Hirschwald; 1885, Berlin.

6. Goldmann EE. Die aüssere und innere Sekretion des gesunden und kranken Organismus im Lichte der "vitalen Färbung", H. Laupp; 1909. Chir. 64 H. 1, 192.

7. Goldmann EE. Vitalfärbung am Zentralnervensystem, Verl. der Akad. der Wiss.; 1913.

8. Stanness KA, Westrum LE, Fornaciari E, Mascagni P, Nelson JA, Stenglein SG, et al. Morphological and functional characterization of an in vitro blood-brain barrier model. Brain Res. 1997;771:329-42.

9. Berezowski V, Landry C, Dehouck MP, Cecchelli R, Fenart L. Contribution of glial cells and pericytes to the mRNA profiles of $\mathrm{P}$ glycoprotein and multidrug resistance-associated proteins in an 
in vitro model of the blood-brain barrier. Brain Res. 2004;1018:1-9.

10. Abbott NJ. Prediction of blood-brain barrier permeation in drug discovery from in vivo, in vitro and in silico models. Drug Discov Today Technol. 2004;1:407-16.

11. Steiner O, Coisne C, Engelhardt B, Lyck R. Comparison of immortalized bEnd5 and primary mouse brain microvascular endothelial cells as in vitro blood-brain barrier models for the study of $\mathrm{T}$ cell extravasation. J Cereb Blood Flow Metab. 2011;31:315-27.

12. Abbott NJ, Patabendige AAK, Dolman DEM, Yusof SR, Begley DJ. Structure and function of the blood-brain barrier. Neurobiol Dis. 2010;37:13-25.

13. Dehouck MP, Dehouck B, Fenart L, Cecchelli R. Blood-brain barrier in vitro. Rapid evaluation of strategies for achieving drug targeting to the central nervous system. In: Couraud PO, Scherman D, editors. Biology and physiology of the blood-brain barrier. New York: Plenum Press; 1996. p. 143-6.

14. Cecchelli R, Berezowski V, Lundquist S, Culot M, Renftel M, Dehouck MP, et al. Modelling of the blood-brain barrier in drug discovery and development. Nat Rev Drug Discov. 2007;6:65061.

15. Perrière N, Yousif S, Cazaubon S, Chaverot N, Bourasset F, Cisternino $\mathrm{S}$, et al. A functional in vitro model of rat blood-brain barrier for molecular analysis of efflux transporters. Brain Res. 2007;1150:1-13.

16. Lanevskij K, Japertas P, Didziapetris R, Petrauskas A. IonizationSpecific Prediction of Blood-brain Permeability. J Pharm Sci. 2009;98:122-34.

17. Stevenson BR, Keon BH. The tight junction: morphology to molecules. Annu Rev Cell Dev Biol. 1998;14:89-109.

18. Mitic LL, Anderson JM. Molecular architecture of tight junctions. Annu Rev Physiol. 1998;60:121-42.

19. Abbott NJ, Ronnback L, Hansson E. Astrocyte-endothelial interactions at the blood-brain barrier. Nat Rev Neurosci. 2006; 7:41-53.

20. Ballabh P, Braun A, Nedergaard M. The blood-brain barrier: an overview: structure, regulation, and clinical implications. Neurobiol Dis. 2004; 16:1-13.

21. Abbott NJ. Astrocyte-endothelial interactions and blood-brain barrier permeability. J Anat. 2002;200:629-38.

22. Crone C, Christensen O. Electrical-resistance of a capillary endothelium. J Gen Physiol. 1981;77:349-71.

23. Butt HJ, Downing KH, Hansma PK. Imaging the membraneprotein bacteriorhodopsin with the atomic force microscope. Biophys J. 1990;58:1473-80.

24. Wolburg H, Lippoldt A. Tight junctions of the blood-brain barrier: Development, composition and regulation. Vasc Pharmacol. 2002;38:II.

25. Doan KMM, Humphreys JE, Webster LO, Wring SA, Shampine LJ, Serabjit-Singh CJ, et al. Passive permeability and Pglycoprotein-mediated efflux differentiate central nervous system (CNS) and non-CNS marketed drugs. J Pharmacol Exp Ther. 2002;303:1029-37.

26. Burns EM, Buschmann MBT, Krukeberg TW, Gaetano PK, Meyer JN. Blood-brain barrier, aging, brain blood flow, and sleep. Adv Neurol. 1981;30:301-6.

27. Cecchelli R, Dehouk B, Descamps L, Fenart L, Buéé-Scherrer V, Duhem $\mathrm{C}$, et al. In vitro model for evaluating drug transport across the blood-brain barrier. Adv Drug Deliv Rev. 1999;36:165-78.

28. Miller DS. Regulation of P-glycoprotein and other ABC drug transporters at the blood-brain barrier. Trends Pharmacol Sci. 2010;31:246-54.

29. Weiss N, Miller F, Gazaubon S, Couraud PO. Biologie de la barrière hématoencéphalique: Partie I. Rev Neurol. 2009;165: 863-74.
30. Petty MA, Lo EH. Junctional complexes of the blood-brain barrier: permeability changes in neuroinflammation. Prog Neurobiol. 2002;68:311-23.

31. Smith MW, Gumbleton M. Endocytosis at the blood-brain barrier: from basic understanding to drug delivery strategies. J Drug Target. 2006;14:191-214.

32. Hawkins BT, Egleton RD. Pathophysiology of the blood-brain barrier: animal models and methods. In: Gerald PS, editor. Current topics in developmental biology. Academic Press; 2007. pp. 277-309. doi:10.1016/S0070-2153(07)80007-X

33. Weiss N, Miller F, Gazaubon S, Couraud PO. The blood-brain barrier in brain homeostasis and neurological diseases. Biochim Biophys Acta. 2009;1788:842-57.

34. Löscher W, Potschka H. Role of drug efflux transporters in the brain for drug disposition and treatment of brain diseases. Prog Neurobiol. 2005;76:22-76.

35. Gao B, Stieger B, Noé B, Fritschy JM, Meier PJ. Localization of the organic anion transporting polypeptide 2 (Oatp2) in capillary endothelium and choroid plexus epithelium of rat brain. J Histochem Cytochem. 1999;47:1255-63.

36. Cordoncardo C, Obrien JP, Casals D, Rittmangrauer L, Biedler JL, Melamed MR, et al. Multidrug-tesistance hene (PGlycoprotein) is rxpressed by rndothelial-cells at blood-brain barrier sites. Proc Natl Acad Sci USA. 1989;86:695-8.

37. Eisenblatter T, Galla HJ. A new multidrug resistance protein at the blood-brain barrier. Biochem Biophys Res Commun. 2002;293:1273-8.

38. Salmina AB. Neuron-glia interactions as therapeutic targets in neurodegeneration. J Alzheimers Dis. 2009;16:485-502.

39. Dehouck MP, Meresse S, Delorme P, FruchartJC, Cecchelli R. An easier, reproductible, and mass-production method to study the blood-brain barrier in vitro. J Neurochem. 1990;54:1798-801.

40. Rubin LL, Hall DE, Porter S, Barbu K, Cannon C, Horner HC, et al. A cell-culture model of the blood-brain-barrier. J Cell Biol. 1991;115:1725-35.

41. Ramsauer M, Krause D, Dermietzel R. Angiogenesis of the blood-brain barrier in vitro and the function of cerebral pericytes. FASEB J. 2002; 16:1274.

42. Sa-Pereira I, Brites D, Brito MA. Neurovascular unit: a focus on Pericytes. Mol Neurobiol. 2012;45:327-47.

43. Alavijeh MS, Chishty M, Qaiser MZ, Palmer AM. Drug metabolism and pharmacokinetics, the blood-brain barrier, and central nervous system drug discovery. Neurotherapeutics. 2005;2:554-71.

44. Chancellor MB, Staskin DR, Kay GG, Sandage BW, Oefelein MG, Tsao JW. Blood-brain barrier permeation and efflux exclusion of anticholinergics used in the treatment of overactive bladder. Drugs Aging. 2012;29:259-73.

45. Summerfield SG, Read K, Begley DJ, Obradovic T, Hidalgo IJ, Coggon S, et al. Central nervous system drug disposition: the relationship between in situ brain permeability and brain free fraction. J Pharmacol Exp Ther. 2007;322:205-13.

46. Lee K, Thakker DR. Saturable transport of H2-antagonists ranitidine and famotidine across Caco-2 cell monolayers. J Pharm Sci. 1999;88:680-7.

47. Zhou SY, Piyapolrungroj N, Pao LH, Li C, Liu GY, Zimmermann E, et al. Regulation of paracellular absorption of cimetidine and 5-aminosalicylate in rat intestine. Pharm Res. 1999;16:1781-5.

48. Flanagan SD, Takahashi LH, Liu XL, Benet LZ. Contributions of saturable active secretion, passive transcellular, and paracellular diffusion to the overall transport of furosemide across adenocarcinoma (Caco-2) cells. J Pharm Sci. 2002;91:1169-77.

49. Leontiadou H, Mark AE, Marrink SJ. Ion transport across transmembrane pores. Biophys J. 2007;92:4209-15.

50. Cirrito JR, Deane R, Fagan AM, Spinner ML, Parsadanian M, Finn MB, et al. P-glycoprotein deficiency at the blood-brain 
barrier increases amyloid-b deposition in an Alzheimer disease mouse model. J Clin Invest. 2005; 115:3285-90.

51. Stamatovic SM, Keep RF, Andjelkovic AV. Brain endothelial cell-cell junctions: How to "Open" the blood brain barrier. Curr Neuropharmacol. 2008;6:179-92.

52. Marroni M, Marchi N, Cucullo L, Abbott NJ, Signorelli K, Janigro D. Vascular and parenchymal mechanisms in multiple drug resistance: a lesson from human epilepsy. Curr Drug Targets. 2003;4:297-304.

53. Pittet CL, Newcombe J, Prat A, Arbour N. Human brain endothelial cells endeavor to immunoregulate CD8 T cells via PD-1 ligand expression in multiple sclerosis. J Neuroinflam. 201 1;8:155.

54. Bennett J, Basivireddy J, Kollar A, Biron KE, Reickmann P, Jefferies WA, et al. Blood-brain barrier disruption and enhanced vascular permeability in the multiple sclerosis model EAE. J Neuroimmunol. 2010;229:180-91.

55. Liu H, Xu X, Yang Z, Deng Y, Liu X, Xie L. Impaired function and expression of P-glycoprotein in blood-brain barrier of streptozotocin-induced diabetic rats. Brain Res. 2006;1123:245-52.

56. Sugano K, Kansy M, Artursson P, Avdeef A, Bendels S, Di L, et al. Coexistence of passive and carrier-mediated processes in drug transport. Nat Rev Drug Discov. 2010;9:597-614.

57. Waring MJ. Lipophilicity in drug discovery. Expert Opin Drug Discov. 2010;5:235-48.

58. Camenisch G, Alsenz J, van de Waterbeemd H, Folkers G. Estimation of permeability by passive diffusion through Caco-2 cell monolayers using the drugs' lipophilicity and molecular weight. Eur J Pharm Sci. 1998;6:313-9.

59. Johnson TW, Dress KR, Edwards M. Using the golden triangle to optimize clearance and oral absorption. Bioorg Med Chem Lett. 2009; 19:5560-4.

60. Pardridge WM. GNS drug design based on principles of bloodbrain barrier transport. J Neurochem. 1998;5:1781-92.

61. Lipinski CA, Lombardo F, Dominy BW, Feeney PJ. Experimental and computational approaches to estimate solubility and permeability in drug discovery and development settings. Adv Drug Deliv Rev. 1997;23:3-25.

62. Zhao YH, Abraham MH, Ibrahim A, Fish PV, Cole S, Lewis ML, et al. Predicting penetration across the blood-brain barrier from simple descriptors and fragmentation schemes. J Chem Inf Model. 2006;47:170-5.

63. Avdeef A. Absorption and drug development. Hoboken: John Wiley \& Sons; 2003

64. Kell DB, Dobson PD, Bilsland E, Oliver SG. The promiscuous binding of pharmaceutical drugs and their transporter-mediated uptake into cells: what we (need to) know and how we can do so. Drug Discov Today. 2013;18(5-6):218-39.

65. Varatharajan L, Thomas SA. The transport of anti-HIV drugs across blood-CNS interfaces: Summary of current knowledge and recommendations for further research. Antivir Res. 2009;82:A99109.

66. Deli MA, Abraham C, Kataoka Y, Niwa M. Permeability studies on in vitro blood-brain barrier models: physiology, pathology, and pharmacology. Cell Mol Neurobiol. 2005;25:59-127.

67. Cecchelli R, Coisne C, Dehouck L, Miller F, Dehouck MP, BuéeScherrer $\mathrm{V}$, et al. Modeling the blood-brain barrier. In: Dermietzel R, Spray DG, Nedergaard M, editors. Blood-brain interfaces. From ontogeny to artificial barriers. Weinheim: WileyVCH Verlag GmbH; 2006. p. 337-55.

68. Nau R, Soergel F, Eiffert H. Penetration of drugs through the blood-cerebrospinal fluid/blood-brain barrier for treatment of central nervous system infections. Clin Microbiol Rev. 2010;23:858. -+.

69. Kroll RA, Neuwelt EA. Outwitting the blood-brain barrier for therapeutic purposes: osmotic opening and other means. Neurosurgery. 1998;42:1083-99.
70. Rapoport SI. Osmotic opening of the blood-brain barrier: principles, mechanism, and therapeutic applications. Cell Mol Neurobiol. 2000;20:217-30.

71. Nicolazzo JA, Charman SA, Charman WN. Methods to assess drug permeability across the blood-brain barrier. J Pharm Pharmacol. 2006;58:281-93.

72. Illum L. Is nose-to-brain transport of drugs in man a reality? J Pharm Pharmacol. 2004;56:3-17.

73. Deli MA. Potential use of tight junction modulators to reversibly open membranous barriers and improve drug delivery. Biochim Biophys Acta. 2009;1788:892-910.

74. Zhang H, Prisinzano TE, Donovan MD. Permeation and metabolism of cocaine in the nasal mucosa. Eur J Drug Metab Pharmacokinet. 2012;37:255-62.

75. Singh AP, Saraf SK, Saraf SA. SLN approach for nose-to-brain delivery of alprazolam. Drug Deliv Transl Res. 2012;2:498-507.

76. Veronesi MC, Kubek DJ, Kubek MJ. Intranasal delivery of neuropeptides. Neuropeptides. 2011;789:303-12.

77. Bousquet L. Etude comparative des thérapies anti-VIH: rôle des transporteurs d'Efflux sur le passage transmembranaire des antirétroviraux au niveau des cellules CD4+ et de la Barrière hémato-encéphalique, Université Paris XI; 2008.

78. Drin G, Rousselle C, Scherrmann JM, Rees AR, Temsamani J. Peptide delivery to the brain via adsorptive-mediated endocytosis: advances with SynB vectors. AAPS Pharm Sci. 2002;4(4):61-7.

79. Malakoutikhah M, Teixido M, Giralt E. Toward an optimal blood-brain barrier shuttle by synthesis and evaluation of peptide libraries. J Math Chem. 2008;51:4881-9.

80. Costantino L, Tosi G, Ruozi B, Bondioli L, Vandelli MA, Forni F. Colloidal systems for CNS drug delivery. In: Hari SS, editor. Progress in Brain Research Nanoneuroscience and Nanoneuropharmacology. Elsevier; 2009. pp. 35-69.

81. Ruozi B, Tosi G, Forni F, Vandelli MA. Ketorolac tromethamine liposomes: encapsulation and release studies. J Liposome Res. 2005; 15:175-85.

82. Ali M, Kirby DJ, Mohammed AR, Perrie Y. Solubilisation of drugs within liposomal bilayers: alternatives to cholesterol as a membrane stabilising agent. J Pharm Pharmacol. 2010;62:164655 .

83. Gabizon AA. Pegylated liposomal doxorubicin: metamorphosis of an old drug into a new form of chemotherapy. Cancer Investig. 2001;19:424-36.

84. Working PK, Dayan AD. Pharmacological-toxicological expert report - Caelyx (TM) - (Stealth $(\mathrm{R})$ liposomal doxorubicin $\mathrm{HCl})$ foreword. Hum Exp Toxicol. 1996;15:751-85.

85. Huwyler J, Wu D, Pardridge WM. Brain drug delivery of small molecules using immunoliposomes. Proc Natl Acad Sci USA. 1996;93:14164-9.

86. Mamot C, Ritschard R, Wicki A, Stehle G, Dieterle T, Bubendorf $\mathrm{L}$, et al. Tolerability, safety, pharmacokinetics, and efficacy of doxorubicin-loaded anti-EGFR immunoliposomes in advanced solid tumours: a phase 1 dose-escalation study. Lancet Oncol. 2012;13:1234-41.

87. Mehlhorn RJ, Sumida S, Packer L. Tocopheroxyl radical persistence and tocopherol consumption in liposomes and in vitamin-Eenriched rat-liver mitochondria and microsomes. J Biol Chem. 1989;264:13448-52.

88. Hiremath PS, Soppimath KS, Betageri GV. Proliposomes of exemestane for improved oral delivery: Formulation and in vitro evaluation using PAMPA, Caco-2 and rat intestine. Int J Pharm. 2009;380:96-104.

89. Kreuter J, Alyautdin RN, Kharkevich DA, Ivanov AA. Passage of peptides through the blood-brain-barrier with colloidal polymer particles (nanoparticles). Brain Res. 1995;674:171-4.

90. Kreuter J. Nanoparticulate systems for brain delivery of drugs. Adv Drug Deliv Rev. 2001;47:65-81. 
91. Wohlfart S, Gelperina S, Kreuter J. Transport of drugs across the blood-brain barrier by nanoparticles. J Control Release. 2012;161:264-73.

92. Costantino L, Boraschi D. Is there a clinical future for polymeric nanoparticles as brain-targeting drug delivery agents? Drug Discov Today. 2012;17:367-78.

93. Lombardo F, Blake JF, Curatolo WJ. Computation of brainblood partitioning of organic solutes via free energy calculations. J Med Chem. 1996;39:4750-5.

94. Abraham MH, Chadha HS, Mitchell RC. Hydrogen bonding. 33. Factors that influence the distribution of solutes between blood and brain. J Pharm Sci. 1994;83:1257-68.

95. Chadha HS, Abraham MH, Mitchell RC. Physicochemical analysis of the factors goverining distribution of solutes between blood and brain. Bioorg Med Chem Lett. 1994;4:2511-6.

96. Abraham MH, Hersey A. In silico models to predict brain uptake. In: Comprehensive Medicinal chemistry II, Elsevier Ltd; 2007. pp. 745-766.

97. Didziapetris R, Japertas P, Avdeef A, Petrauskas A. Classification analysis of P-glycoprotein substrate specificity. J Drug Target. 2003;11:391-406.

98. Timmermans PBMWM, Brands A, van Zwieten NS. Lipophilicity and brain disposition of clonidine and structurally related imidazolidines. Arch Pharm. 1977;300:217-26.

99. Salminen T, Pulli A, Taskinen J. Relationship between immobilised artificial membrane chromatographic retention and the brain penetration of structurally diverse drugs. J Pharm Biomed Anal. 1997;15:469-77.

100. Taillardat-Bertschinger A, Carrupt PA, Barbato F, Testa B. Immobilized artificial membrane (IAM)-HPLC in drug research. J Med Chem. 2003;46:655-65.

101. Taillardat-Bertschinger A, Galland A, Carrupt PA, Testa B. Immobilized artificial membrane (IAM)-HPLC: proposed guidelines for technical optimization of retention measurements. J Chromatogr A. 2002;953:39-53.

102. Taillardat-Bertschinger A, Marca-Martinet CA, Carrupt PA, Reist M, Caron G, Fruttero R, et al. Molecular factors influencing retention on immobilized artificial membranes (IAM) compared to partitioning in liposomes and n-octanol. Pharm Res. 2002;19:729-37.

103. Taillardat-Bertschinger A, Barbato F, Quercia MT, Carrupt PA, Reist M, La Rotonda MI, et al. Structural properties governing retention mechanisms on immobilized artificial membrane (IAM) HPLC-columns. Helv Chim Acta. 2002;85: 519-32.

104. Ong S, Liu H, Qiu X, Bhat G, Pidgeon G. Membrane partition coefficients chromatographically measured using immobilized artificial membrane surfaces. Anal Chem. 1995;67: 755-62.

105. Pidgeon C, Ong S, Liu H, Qiu X, Pidgeon M, Dantzig M, et al. IAM chromatography: an in vitro screen for predicting drug membrane permeability. J Med Chem. 1995;38:590-4.

106. Stenberg P, Norinder U, Luthman K, Artursson P. Experimental and computational screening models for the prediction of instestinal drug absorption. J Med Chem. 2001;44:1927-37.

107. Osterberg T, Svensson M, Lundahl P. Chromatographic retention of drug molecules on immobilised liposomes prepared from egg phospholipids molecules and from chemically pure phospholipids. Eur J Pharm Sci. 2001;12:427-39.

108. Kansy M, Senner F, Gubernator K. Physicochemical high throughput screening: parallel artificial membrane permeation assay in the description of passive absorption processes. J Med Chem. 1998;41:1007-10.

109. Han M, Fu S, Gao JQ, Fang XL. Evaluation of intestinal absorption of Ginsenoside $\operatorname{Rg}(1)$ incorporated in microemulison using parallel artificial membrane permeability assay. Biol Pharm Bull. 2009;32:1069-74.
110. Wohnsland F, Faller B. High-throughput permeability $\mathrm{pH}$ profile and high-throughput alkane/water $\log \mathrm{P}$ with artificial membranes. J Med Chem. 2001;44:923-30.

111. Ottaviani G, Martel S, Carrupt PA. Parallel artificial membrane permeability assay: a new membrane for the fast prediction of passive human skin permeability. J Med Chem. 2006;49:3948-54.

112. Di L, Kerns EH, Fan K, McConnell OJ, Carter GT. High throughput artificial membrane permeability assay for bloodbrain barrier. Eur J Med Chem. 2003;38:223-32.

113. Di L, Kerns EH, Ma XJ, Huang YP, Carter GT. Applications of high throughput microsomal stability assay in drug discovery. Comb Chem High Throughput Screen. 2008;11:469-76.

114. Di L, Kerns EH, Bezar IF, Petusky SL, Huang YP. Comparison of blood-brain barrier permeability assays: in situ brain perfusion, MDR1-MDCKII and PAMPA-BBB. J Pharm Sci. 2009;98:1980-91.

115. Mensch J, Melis A, Mackie C, Verreck G, Brewster ME, Augustijns P. Evaluation of various PAMPA models to identify the most discriminating method for the prediction of BBB permeability. Eur J Pharm Biopharm. 2010;74:495-502.

116. Passeleu Le Bourdonnec C, Boccard J, Rudaz S, Carrupt PA, Martel $\mathrm{S}$. Evaluation of BBB permeation with PAMPA thanks to a new artificial membrane. In: Frontiers in medicinal chemistry FMC 2011 Stockholm Sweden June 19-21, 2011, 2011. Poster presentation.

117. Dehouck MP, Meresse S, Delbart C, Delorme P, Fruchart JC, Cecchelli R. Co-culture of astrocytes and brain endothelial cells: a potential model for in vitro studies of blood-brain barrier. J Neurochem. 1989;52(Supplement):120.

118. Liu X, Tu M, Kelly KS, Chen C, Smith BJ. Development of a computational approach to predict blood-brain barrier permeability. Drug Metab Dispos. 2004:32:132-9.

119. Mathot F, Schanck A, van Bambeke F, Aridn A, Noppe M, Brewster M, et al. Passive diffusion of polymeric surfactants across lipid bilayers. J Control Release. 2007;120:79-87.

120. Kansy M, Fischer H, Kratzat K, Senner F, Wagner B, Parrilla I. High-throughput artificial membrane permeability studies in early lead discovery and development. In: Testa B, van de Waterbeemd H, Folkers G, Guy RH, editors. Pharmacokinetic optimization in drug research: biological, physicochemical and computational strategies. Zurich: Wiley-VHCA; 2001. p. 447-64.

121. Lundquist S, Renftel M, Brillault J, Fenart L, Cecchelli R, Dehouck MP. Prediction of drug transport through the bloodbrain barrier in vivo: a comparison between two in vitro cell models. Pharm Res. 2002;19:976-81.

122. Pardridge WM. The blood-brain barrier and neurotherapeutics. Neurotherapeutics. 2005;2:1-2.

123. Garberg P, Ball M, Borg N, Cecchelli R, Fenart L, Hurst RD, et al. In vitro models for the blood-brain barrier. Toxicol in Vitro. 2005; 19:299-334.

124. Gumbleton M, Audus KL. Progress and limitations in the use of in vitro cell cultures to serve as a permeability screen for the blood-brain barrier. J Pharm Sci. 2001;90:1681-98.

125. Avdeef A. How well can in vitro brain microcapillary endothelial cell models predict rodent in vivo blood-brain barrier permeability? Eur J Pharm Sci. 2011;43:109-24.

126. Bickel U. How to measure drug transport across the blood-brain barrier. NeuroRx. 2005;2:15-26.

127. Abbruscato TJ, Davis TP. Combination of hypoxia/aglycemia compromises in vitro blood-brain barrier integrity. J Pharmacol Exp Ther. 1999;289:668-75.

128. Audus KL, Borchardt RT. Characteristics of the large neutral amino acid transport system of bovine brain microvessel endothelial cell monolayers. J Neurochem. 1986;47:484-8.

129. Audus KL, Borchardt RT. Characterization of an invitro bloodbrain-barrier model system for studying drug transport and metabolism. Pharm Res. 1986;3:81-7. 
130. Bowman PD, Ennis SR, Rarey KE, Betz AL, Goldstein GW. Brain microvessel endothelial-cells in tissue-culture - A model for study of blood-brain-barrier permeability. Ann Neurol. 1983;14:396-402.

131. Eddy EP, Maleef BE, Hart TK, Smith PL. In vitro models to predict blood-brain barrier permeability. Adv Drug Deliv Rev. 1997;23:185-98.

132. Letrent SP, Polli JW, Humphreys JE, Pollack GM, Brouwer KR, Brouwer KLR. P-glycoprotein-mediated transport of morphine in brain capillary endothelial cells. Biochem Pharmacol. 1999;58:951-7.

133. Pirro JP, Dirocco RJ, Narra RK, Nunn AD. Relationship between in-vitro transendothelial permeability and in-vivo single-pass brain extraction. J Nucl Med. 1994;35:1514-9.

134. Raub TJ, Kuentzel SL, Sawada GA. Permeability of bovine brain microvessel endothelial cells in vitro: Barrier tightening by a factor released from astroglioma cells. Exp Cell Res. 1992;199:330-40.

135. Smith KR, Borchardt RT. Permeability and mechanism of albumin, cationized albumin, and glycosylated albumin trans-cellular transport across monolayers of cultured bovine brain capillary endothelial-cells. Pharm Res. 1989;6:466-73.

136. van Bree JBMM, de Boer AG, Danhof M, Ginsel LA, Breimer DD. Characterization of an in vitro blood-brain barrier: effects of molecular size and lipophilicity on cerebrovascular endothelial transport rates of drugs. J Pharmacol Exp Ther. 1988;247:1233-9.

137. Wang W, Dentler WL, Borchardt RT. VEGF increases BMEC monolayer permeability by affecting occludin expression and tight junction assembly. Am J Physiol Heart Circ Physiol. 2001;280: H434-40.

138. Fischer S, Clauss M, Wiesnet M, Renz D, Schaper W, Karliczek GF. Hypoxia induces permeability in brain microvessel endothelial cells via VEGF and NO. Am J Physiol Cell Physiol. 1999;276:C812-20.

139. Fischer S, Renz D, Schaper W, Karliczek GF. In vitro effects of dexamethasone on hypoxia-induced hyperpermeability and expression of vascular endothelial growth factor. Eur J Pharmacol. 2001;411:231-43.

140. Fischer S, Renz D, Schaper W, Karliczek GF. Effects of barbiturates on hypoxic cultures of brain derived microvascular endothelial cells. Brain Res. 1996;707:47-53.

141. Fischer S, Renz D, Schaper W, Karliczek GF. Barbiturates decrease the expression of vascular endothelial growth factor in hypoxic cultures of porcine brain derived microvascular endothelial cells. Mol Brain Res. 1998;60:89-97.

142. Fischer S, Wobben M, Kleinstuck J, Renz D, Schaper W. Effect of astroglial cells on hypoxia-induced permeability in PBMEC cells. Am J Physiol Cell Physiol. 2000;279:C935-44.

143. Ichikawa N, Naora K, Hirano H, Hashimoto M, Masumura S, Iwamoto $\mathrm{K}$. Isolation and primary culture of rat cerebral microvascular endothelial cells for studying drug transport in vitro. J Pharmacol Toxicol Methods. 1996;36:45-52.

144. Annunziata P, Cioni C, Toneatto S, Paccagnini E. HIV-1 gp120 increases the permeability of rat brain endothelium cultures by a mechanism involving substance P. AIDS. 1998;12:2377-85.

145. Demeuse P, Kerkhofs A, Struys-Ponsar C, Knoops B, Remacle C, de Aguilar PV. Compartmentalized coculture of rat brain endothelial cells and astrocytes: a syngenic model to study the bloodbrain barrier. J Neurosci Methods. 2002;121:21-31.

146. Sahagun G, Moore SA, Hart MN. Permeability of neutral vs anionic dextrans in cultured brain microvascular endothelium. Am J Physiol. 1990;259:H162-6.

147. Imaizumi S, Kondo T, Deli MA, Gobbel G, Joo F, Epstein CJ, et al. The influence of oxygen free radicals on the permeability of the monolayer of cultured brain endothelial cells. Neurochem Int. 1996;29:205-11.

148. Muruganandam A, Herx LM, Monette R, Durkin JP, Stanimirovic DB. Development of immortalized human cerebromicrovascular endothelial cell line as in vitro model of the human blood-brain barrier. FASEB J. 1997;11:1187.

149. Mackic JB, Stins M, Mccomb JG, Calero M, Ghiso J, Kim KS, et al. Human blood-brain barrier receptors for Alzheimer's amyloid-beta 1-40 - Asymmetrical binding, endocytosis, and transcytosis at the apical side of brain microvascular endothelial cell monolayer. J Clin Invest. 1998;102:734-43.

150. Stins MF, Badger J, Sik Kim K. Bacterial invasion and transcytosis in transfected human brain microvascular endothelial cells. Microb Pathog. 2001;30:19-28.

151. Jong AY, Stins MF, Huang SH, Chen SHM, Kim KS. Traversal of Candida albicans across human blood-brain barrier In vitro. Infect Immun. 2001;69:4536-44.

152. Megard I, Garrigues A, Orlowski S, Jorajuria S, Clayette P, Ezan E, et al. A co-culture-based model of human blood-brain barrier: application to active transport of indinavir and in vivo-in vitro correlation. Brain Res. 2002;927:153-67.

153. Yang T, Roder KE, Abbruscato TJ. Evaluation of bEnd5 cell line as an in vitro model for the blood-brain barrier under normal and hypoxic/aglycemic conditions. J Pharm Sci. 2007;96:3196-213.

154. Zenker D, Begley D, Bratzke H, Rübsamen-Waigmann H, von Briesen H. Human blood-derived macrophages enhance barrier function of cultured primary bovine and human brain capillary endothelial cells. J Physiol. 2003;551:1023-32.

155. Schulze C, Smales C, Rubin LL, Staddon JM. Lysophosphatidic acid increases tight junction permeability in cultured brain endothelial cells. J Neurochem. 1997;68:991-1000.

156. Gloor SM, Weber A, Adachi N, Frei K. Interleukin-1 modulates protein tyrosine phosphatase activity and permeability of brain endothelial cells. Biochem Biophys Res Commun. 1997;239:804-9.

157. Hoheisel D, Nitz T, Franke H, Wegener J, Hakvoort A, Tilling T, Galla HJ. Hydrocortisone reinforces the blood-brain barrier properties in a serum free cell culture system (vol 244, pg 312, 1998). Biochem Biophys Res Commun. 1998;247:536-+.

158. Tilling T, Korte D, Hoheisel D, Galla HJ. Basement membrane proteins influence brain capillary endothelial barrier function in vitro. J Neurochem. 1998;71:1151-7.

159. Franke H, Galla HJ, Beuckmann CT. An improved lowpermeability in vitro-model of blood-brain barrier: transport studies on retinoids, sucrose, haloperidol, caffeine and mannitol. Brain Res. 1999;818:65-71.

160. Nitz T, Eisenblatter T, Psathaki K, Galla HJ. Serum-derived factors weaken the barrier properties of cultured porcine brain capillary endothelial cells in vitro. Brain Res. 2003;981:30-40.

161. Igarashi Y, Utsumi H, Chiba H, Yamada-Sasamori Y, Tobioka $\mathrm{H}$, Kamimura $\mathrm{Y}$, et al. Glial cell line-derived neurotrophic factor induces barrier function of endothelial cells forming the bloodbrain barrier. Biochem Biophys Res Commun. 1999;261:108-12.

162. Yamagata K, Tagami M, Takenaga F, Yamori Y, Nara Y, Itoh S. Polyunsaturated fatty acids induce tight junctions to form in brain capillary endothelial cells. Neuroscience. 2003;116:649-56.

163. Franke H, Galla HJ, Beuckmann CT. Primary cultures of brain microvessel endothelial cells: a valid and flexible model to study drug transport through the blood-brain barrier in vitro. Brain Res Protocol. 2000;5:248-56.

164. Lohmann C, Hüwel S, Galla HJ. Predicting blood-brain barrier permeability of drugs: evaluation of different in vitro assays. $\mathrm{J}$ Drug Target. 2002;10:263-76.

165. Smith M, Omidi Y, Gumbleton M. Primary porcine brain microvascular endothelial cells: biochemical and functional characterisation as a model for drug transport and targeting. J Drug Target. 2007;15:253-68.

166. Bernas MJ, Cardoso FL, Daley SK, Weinand ME, Campos AR, Ferreira AJG, et al. Establishment of primary cultures of human brain microvascular endothelial cells to provide an in vitro cellular model of the blood-brain barrier. Nat Protoc. 2010;5:1265-72. 
167. Ramirez SH, Hasko J, Skuba A, Fan S, Dykstra H, McCormick R, et al. Activation of cannabinoid receptor 2 attenuates leukocyteendothelial cell interactions and blood-brain barrier dysfunction under inflammatory conditions. J Neurosci. 2012;32:4004-16.

168. Benistant G, Dehouck MP, Fruchart JC, Cecchelli R, Lagarde M. Fatty-acid composition of brain capillary endothelial-cells - effect of the coculture with astrocytes. J Lipid Res. 1995;36:2311-9.

169. Edgell GJ, Mcdonald GC, Graham JB. Permanent cell-line expressing human factor-Viii-related antigen established by hybridization. Proc Natl Acad Sci USA. 1983;80:3734-7.

170. Shay JW, Wright WE, Werbin H. Defining the molecular mechanisms of human cell immortalization. Biochim Biophys Acta. 1991;1072:1-7.

171. Kirinaka H, Miyake K, Iijima S. Isolation of immortal human endothelial cells. Biosci Biotechnol Biochem. 1995;59:912-4.

172. Roux F, Durieu-Trautmann O, Chaverot N, Claire M, Mailly P, Bourre JM, et al. Regulation of g-glutamyl transpeptidase and alkaline phosphatase activities in immortalized rat brain microvessel endothelial cells. J Cell Physiol. 1994;159:101-13.

173. Sobue K, Yamamoto N, Yoneda K, Hodgson ME, Yamashiro K, Tsuruoka N, et al. Induction of blood-brain barrier properties in immortalized bovine brain endothelial cells by astrocytic factors. Neurosci Res. 1999;35:155-64.

174. Weksler BB, Subileau EA, Perriere N, Charneau P, Holloway K, Leveque $\mathrm{M}$, et al. Blood-brain barrier-specific properties of a human adult brain endothelial cell line. FASEB J. 2005;19:187. -+.

175. Kannan R, Chakrabarti R, Tang D, Kim KJ, Kaplowitz N. GSH transport in human cerebrovascular endothelial cells and human astrocytes: evidence for luminal localization of $\mathrm{Na}+-$ dependent GSH transport in HCEC. Brain Res. 2000;852:374-82.

176. Gu X, Zhang J, Brann DW, Yu FS. Brain and retinal vascular endothelial cells with extended life span established by ectopic expression of telomerase. Invest Ophthalmol Vis Sci. 2003;44:3219-25.

177. Hurst RD, Fritz IB. Properties of an immortalised vascular endothelial/glioma cell co-culture model of the blood-brain barrier. J Cell Physiol. 1996;167:81-8.

178. Hurst RD, Heales SJR, Dobbie MS, Barker JE, Clark JB. Decreased endothelial cell glutathione and increased sensitivity to oxidative stress in an in vitro blood-brain barrier model system. Brain Res. 1998;802:232-40.

179. Dobbie MS, Hurst RD, Klein NJ, Surtees RAH. Upregulation of intercellular adhesion molecule-1 expression on human endothelial cells by tumour necrosis factor-alpha in an in vitro model of the blood-brain. Brain Res. 1999;830:330-6.

180. Scism JL, Laska DA, Horn JW, Gimple JL, Pratt SE, Shepard RL, et al. Evaluation of an in vitro coculture model for the blood-brain barrier: comparison of human umbilical vein endothelial cells (ECV304) and rat glioma cells (C6) from two commercial sources. In Vitro Cell Dev Biol Anim. 1999;35(10):580-92.

181. Easton AS, Abbott NJ. Bradykinin increases permeability by calcium and 5-lipoxygenase in the ECV304/C6 cell culture model of the blood-brain barrier. Brain Res. 2002;953:157-69.

182. Hosoya K, Tetsuka K, Nagase K, Tomi M, Saeki S, Ohtusuki S, et al. Conditionally immortalized brain capillary endothelial cell lines established from a transgenic mouse harboring temperaturesensitive simian virus 40 large T-antigen gene. AAPS Pharm Sci. 2000;2:1-11.

183. Youdim KA, Dobbie MS, Kuhnle G, Proteggente AR, Abbott NJ, Rice-Evans C. Interaction between flavonoids and the bloodGÇôbrain barrier: in vitro studies. J Neurochem. 2003;85:180-92.

184. Rist RJ, Romero IA, Chan MWK, Couraud PO, Roux F, Abbott NJ. F-actin cytoskeleton and sucrose permeability of immortalised rat brain microvascular endothelial cell monolayers: effects of cyclic AMP and astrocytic factors. Brain Res. 1997;768:10-8.
185. Mertsch K, Blasig I, Grune T. 4-Hydroxynonenal impairs the permeability of an in vitro rat blood-brain barrier. Neurosci Lett. 2001;314:135-8.

186. Romero IA, Rist RJ, Aleshaiker A, Abbott NJ. Metabolic and permeability changes caused by thiamine deficiency in immortalized rat brain microvessel endothelial cells. Brain Res. 1997;756:133-40.

187. Romero IA, Prevost MC, Perret E, Adamson P, Greenwood J, Couraud PO, et al. Interactions between brain endothelial cells and human T-cell leukemia virus type 1-infected lymphocytes: Mechanisms of viral entry into the central nervous system. J Virol. 2000;74:6021-30.

188. Romero IA, Radewicz K, Jubin E, Michel CC, Greenwood J, Couraud PO, et al. Changes in cytoskeletal and tight junctional proteins correlate with decreased permeability induced by dexamethasone in cultured rat brain endothelial cells. Neurosci Lett. 2003;344:112-6.

189. Poller B, Gutmann H, Krahenbuhl S, Weksler B, Romero I, Couraud PO, et al. The human brain endothelial cell line hCMEC/D3 as a human blood-brain barrier model for drug transport studies. J Neurochem. 2008;107:1358-68.

190. Kiss L, Walter FR, Bocsik A, Veszelka S, Ozsvari B, Puskas LG, et al. Kinetic analysis of the toxicity of pharmaceutical excipients cremophor EL and RH40 on endothelial and epithelial cells. J Pharm Sci. 2013;102(4):1173-81.

191. Daniels BP, Cruz-Orengo L, Pasieka TJ, Couraud PO, Romero IA, Weksler B, et al. Immortalized human cerebral microvascular endothelial cells maintain the properties of primary cells in an in vitro model of immune migration across the blood brain barrier. J Neurosci Methods. 2013;212:173-9.

192. Ohtsuki S, Ikeda C, Uchida Y, Sakamoto Y, Miller F, Glacial F, et al. Quantitative targeted absolute proteomic analysis of transporters, receptors and junction proteins for validation of human cerebral microvascular endothelial cell lne hCMEC/D3 as a human blood-brain barrier model. Mol Pharm. 2012;10:289-96.

193. Markoutsa E, Pampalakis G, Niarakis A, Romero IA, Weksler B, Couraud PO, et al. Uptake and permeability studies of BBBtargeting immunoliposomes using the hCMEC/D3 cell line. Eur J Pharm Biopharm. 2011;77:265-74.

194. Nakagawa S, Deli MA, Kawaguchi H, Shimizudani T, Shimono $\mathrm{T}$, Kittel A, et al. A new blood-brain barrier model using primary rat brain endothelial cells, pericytes and astrocytes. Neurochem Int. 2009;54:253-63.

195. Gaillard PJ, Voorwinden LH, Nielsen JL, Ivanov A, Atsumi R, Engman $\mathrm{H}$, et al. Establishment and functional characterization of an in vitro model of the blood-brain barrier, comprising a coculture of brain capillary endothelial cells and astrocytes. Eur J Pharm Sci. 2001;12:215-22.

196. Janzer RC, Raff MC. Astrocytes induce blood-brain barrier properties in endothelial cells. Nature. 1987;325:253-7.

197. Fenart L, Buee-Scherrer V, Descamps L, Duhem C, Poullain MG, Cecchelli R, et al. Inhibition of P-glycoprotein: rapid assessment of its implication in blood-brain barrier integrity and drug transport to the brain by an in vitro model of the blood-brain barrier. Pharm Res. 1998;15:993-1000.

198. Calabria AR, Weidenfeller G, Jones AR, De Vries HE, Shusta EV. Puromycin-purified rat brain microvascular endothelial cell cultures exhibit improved barrier properties in response to glucocorticoid induction. J Neurochem. 2006;97:922-33.

199. Dohgu S, Takata F, Yamauchi A, Nakagawa S, Egawa T, Naito $\mathrm{M}$, et al. Brain pericytes contribute to the induction and upregulation of blood-brain barrier functions through transforming growth factor-beta production. Brain Res. 2005;1038:208-15.

200. Dehouck MP, Jolliet-Riant P, Brée F, Fruchart JC, Cecchelli R, Tillement JP. Drug transfer across the blood-brain barrier: correlation between in vitro and in vivo models. J Neurochem. 1992;58:1790-7. 
201. Wang Q, Rager JD, Weinstein K, Kardos PS, Dobson GL, Li JB, et al. Evaluation of the MDR-MDCK cell line as a permeability screen for the blood-brain barrier. Int J Pharm. 2005;288:349-59.

202. Hakkarainen JJ, Jalkanen AJ, Kääriäinen TM, Keski-Rahkonen $\mathrm{P}$, Venäläinen T, Hokkanen J, et al. Comparison of in vitro cell models in predicting in vivo brain entry of drugs. Int $\mathrm{J}$ Pharm. 2010;402:27-36.

203. Lacombe O, Videau O, Chevillon D, Guyot AC, Contreras C, Blondel $\mathrm{S}$, et al. In vitro primary human and animal cell-based blood-brain barrier models as a screening tool in drug discovery. Mol Pharm. 2011;8:651-63.

204. Ball K, Bouzom F, Scherrmann JM, Walther B, Declèves X. Development of a physiologically based pharmacokinetic model for the rat central nervous system and determination of an in vitroin vivo scaling methodology for the blood-brain barrier permeability of two transporter substrates, morphine and oxycodone. J Pharm Sci. 2012;101:4277-92.

205. Lu W, Tan YZ, Jiang XG. Establishment of coculture model of blood-brain barrier in vitro for nanoparticle's transcytosis and toxicity evaluation. Acta Pharm Sin. 2006;41:296-304.

206. Ragnaill MN, Brown M, Ye D, Bramini M, Callanan S, Lynch I, et al. Internal benchmarking of a human blood-brain barrier cell model for screening of nanoparticle uptake and transcytosis. Eur J Pharm Biopharm. 2011;77:360-7.

207. Yousif S, Marie-Claire C, Roux F, Scherrmann JM, Declèves X. Expression of drug transporters at the blood-brain barrier using an optimized isolated rat brain microvessel strategy. Brain Res. 2007;1134:1-11

208. Miller DS, Nobmann SN, Gutmann H, Toeroek M, Drewe J, Fricker G. Xenobiotic transport across isolated brain microvessels studied by confocal microscopy. Mol Pharmacol. 2000;58:135767.

209. Durk MR, Chan GN, Campos CR, Peart JC, Chow EC, Lee E, et al. 1a,25-Dihydroxyvitamin D3-liganded vitamin D receptor increases expression and transport activity of P-glycoprotein in isolated rat brain capillaries and human and rat brain microvessel endothelial cells. J Neurochem. 2012;123:944-53.

210. Pardridge WM. $\log (\mathrm{BB})$, PS products and in silico models of drug brain penetration. Drug Discov Today. 2004;9:392-3.

211. Boje KMK. In vivo measurement of blood-brain barrier permeability. In: Current Protocols in Neuroscience. John Wiley \& Sons, Inc.; 2001.

212. Ohno K, Pettigrew KD, Rapoport SI. Lower limits of cerebrovascular permeability to nonelectrolytes in the conscious rat. Am J Physiol Heart Circ Physiol. 1978;235:H299-307.

213. Kalvass JC, Maurer TS, Pollack GM. Use of plasma and brain unbound fractions to assess the extent of brain distribution of 34 drugs: comparison of unbound concentration ratios to in vivo $\mathrm{P}$ glycoprotein efflux ratios. Drug Metab Dispos. 2007;35:660-6.

214. Young RC, Mitchell RG, Brown TH, Ganellin GR, Griffiths R, Jones M, et al. Development of a new physicochemical model for brain penetration and its application to the design of centrally acting $\mathrm{H}_{2}$ receptor histamine antagonists. J Med Chem. 1988;31:656-71.

215. Rohanova M, Balikova M. Studies on distribution and metabolism of para-methoxymethamphetamine (PMMA) in rats after subcutaneous administration. Toxicology. 2009;259:61-8.

216. Friden M, Ljungqvist $\mathrm{H}$, Middleton B, Bredberg U, Hammarlund-Udenaes M. Improved measurement of drug exposure in the brain using drug-specific correction for residual blood. J Cereb Blood Flow Metab. 2009;30:150-61.

217. Dash AK, Elmquist WF. Separation methods that are capable of revealing blood-brain barrier permeability. J Chromatogr B. 2003; 797:241-54

218. Elmquist WF, Sawchuk RJ. Application of microdialysis in pharmacokinetic studies. Pharm Res. 1997;14:267-88.
219. Gupta A, Chatelain P, Massingham R, Jonsson EN, HammarlundUdenaes M. Brain distribution of cetirizin enantiomers: comparison of three different tissue-to-plasma partition coefficients: Kp, Kp, u, and Kp, uu. Drug Metab Dispos. 2006;34(2):318-23.

220. Friden M, Ducrozet F, Middleton B, Antonsson M, Bredberg U, Hammarlund-Udenaes M. Development of a high-throughput brain slice method for studying drug distribution in the central nervous system. Drug Metab Dispos. 2009;37:1226-33.

221. Friden M, Gupta A, Antonsson M, Bredberg U, HammarlundUdenaes M. In vitro methods for estimating unbound drug concentrations in the brain interstitial and intracellular fluids. Drug Metab Dispos. 2007;35:1711-9.

222. Bonate PL. Animal-models for studying transport across the blood-brain-barrier. J Neurosci Methods. 1995;56:1-15.

223. Oldendorf WH, Stoller BE, Tishler TA, Williams JL, Oldendorf SZ. Transient blood-brain barrier passage of polar compounds at low pH. Am J Physiol Heart Circ Physiol. 1994;267:H2229-36.

224. Takasato Y, Rapoport SI, Smith QR. An insitu brain perfusion technique to study cerebrovascular transport in the rat. Am J Physiol. 1984;247:H484-93.

225. Cannon RE, Peart JC, Hawkins BT, Campos CR, Miller DS. Targeting blood-brain barrier sphingolipid signaling reduces basal P-glycoprotein activity and improves drug delivery to the brain. Proc Natl Acad Sci. 2012;109:15930-5.

226. Kakee A, Terasaki T, Sugiyama Y. Selective brain to blood efflux transport of para-aminohippuric acid across the blood-brain barrier: in vivo evidence by use of the brain efflux index method. J Pharmacol Exp Ther. 1997;283:1018-25.

227. Syvänen S, Eriksson J. Advances in PET imaging of Pglycoprotein function at the blood-brain barrier. ACS Chem Neurosci.; 2013;4(2):225-37.

228. Wanek T, Kuntner C, Bankstahl JP, Mairinger S, Bankstahl M, Stanek J, et al. A novel PET protocol for visualization of breast cancer resistance protein function at the blood-brain barrier. J Cereb Blood Flow Metab. 2012;32:2002-11.

229. Knight RA, Karki K, Ewing JR, Divine GW, Fenstermacher JD, Patlak CS, et al. Estimating blood and brain concentrations and blood-to-brain influx by magnetic resonance imaging with stepdown infusion of Gd-DTPA in focal transient cerebral ischemia and confirmation by quantitative autoradiography with Gd[lsqb] 14C[rsqb]DTPA. J Cereb Blood Flow Metab. 2009;29:1048-58.

230. Serres S, Soto MS, Hamilton A, McAteer MA, Carbonell WS, Robson MD, et al. Molecular MRI enables early and sensitive detection of brain metastases. Proc Natl Acad Sci. 2012;109: 6674-9.

231. van de Ven KCG, van der Graaf M, Tack CJ, Heerschap A, de Galan BE. Steady-state brain glucose concentrations during hypoglycemia in healthy humans and patients with type 1 diabetes. Diabetes. 2012;61:1974-7.

232. Culot M, Lundquist S, Vanuxeem D, Nion S, Landry C, Delplace $\mathrm{Y}$, et al. An in vitro blood-brain barrier model for high throughput (HTS) toxicological screening. Toxicol in Vitro. 2008;22:799811.

233. Sano Y, Shimizu F, Abe M, Maeda T, Kashiwamura Y, Ohtsuki $\mathrm{S}$, et al. Establishment of a new conditionally immortalized human brain microvascular endothelial cell line retaining an in vivo bloodGÇôbrain barrier function. J Cell Physiol. 2010;225:51928.

234. Balbuena P, Li W, Magnin-Bissel G, Meldrum JB, Ehrich M. Comparison of two blood-brain barrier in vitro systems: cytotoxicity and transfer assessments of malathion/oxon and lead acetate. Toxicol Sci. 2010;114:260-71.

235. Roux F, Gouraud PO. Rat brain endothelial cell lines for the study of blood-brain barrier permeability and transport functions. Cell Mol Neurobiol. 2005;25:41-57. 
236. Shayan G, Choi YS, Shusta EV, Shuler ML, Lee KH. Murine in vitro model of the blood-brain barrier for evaluating drug transport. Eur J Pharm Sci. 2011;42:148-55.

237. Coisne C, Dehouck L, Faveeuw C, Delplace Y, Miller F, Landry $\mathrm{C}$, et al. Mouse syngenic in vitro blood-brain barrier model: a new tool to examine inflammatory events in cerebral endothelium. Lab Investig. 2005;85:734-46.
238. Dehouck B, Dehouck MP, Fruchart JC, Cecchelli R. Upregulation of the low-density-lipoprotein receptor at the blood-brain-barrier Intercommunications between brain capillary endothelial-cells and astrocytes. J Cell Biol. 1994;126:465-73.

239. Descamps L, Dehouck MP, Torpier G, Cecchelli R. Receptormediated transcytosis of transferrin through blood-brain barrier endothelial cells. Am J Physiol Heart Circ Physiol. 1996;270:H1 149-58. 